Research Paper

\title{
Spatiotemporal Characteristics of Particulate Matters \\ Concentration and Their Influence on Ambient Air Quality in Urban Regions of Khuzestan Province, Iran
}

\author{
Nasrin Hassanzadeh $^{1^{*}}$ (D), Fariba Hedayatzadeh ${ }^{1}$ (D)
}

1. Department of Environment Sciences, Faculty of Natural Resources and Environment, Malayer University, Malayer, Iran

\begin{tabular}{|l|l|}
\hline $\begin{array}{c}\text { Use your device to scan } \\
\text { and read the article online }\end{array}$ \\
Influence on Ambient Air Quality in Urban Regions of Khuzestan Province, Iran. Journal of Advances in Environmental Health \\
Research. 2021; 9(3):209-226. http://dx.doi.org/10.32598/JAEHR.9.3.1213 \\
doi http://dx.doi.org/10.32598/JAEHR.9.3.1213
\end{tabular}

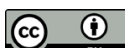

Article info:

Received: 19 Apr 2020

Accepted: 29 Jun 2020

Publish: 01 Jul 2021

\section{Keywords:}

Particulate matter, Air quality index, Exceedance factor, Khuzestan Province, Iran

\section{A B S T RACT}

Background: One of the most concerning pollutants in urban areas across the globe is particulate matter suspended in the Earth's atmosphere. The main objective of the current investigation is to explore the spatial and temporal patterns of ambient air particles $\left(\mathrm{PM}_{10}\right.$ and $\left.\mathrm{PM}_{2.5}\right)$ and $\mathrm{PM}_{2.5} /$ $\mathrm{PM}_{10}$ ratio in different urban areas of Khuzestan Province.

Methods: In this way, the required data were gathered from the environmental protection organization based on hourly mean concentrations of $\mathrm{PM}_{10}$ and $\mathrm{PM}_{2.5}$ of six air pollutionmonitoring sites for 5 years.

Results: Results indicated that the average concentrations of $\mathrm{PM}_{10}, \mathrm{PM}_{2.5}$, and $\mathrm{PM}_{2.5} / \mathrm{PM}_{10}$ are about $134.14 \pm 39.23 \mu \mathrm{g} / \mathrm{m}^{3}, 44.51 \pm 13.44 \mu \mathrm{g} / \mathrm{m}^{3}$ and $0.33 \pm 0.07$, respectively. The examinations revealed a reductive trend on annual values of PMs in terms of temporal variations. A detailed investigation of the annual mean concentrations of $\mathrm{PMs}$ and $\mathrm{PM}_{2.5} / \mathrm{PM}_{10}$ in terms of spatial variations demonstrated the largest values for Naderi-Ahvaz and Abadan stations. Furthermore, the measured AQI was larger than 100 and the Exceedance Factor $(E F)$ values of $\mathrm{PM}_{10}$ and $\mathrm{PM}_{2.5}$ ranged between 1.51-2.73 and 0.77-1.41. The statistical analysis obtained from linear regression revealed a significant positive relation between $\mathrm{AQI}$ and $\mathrm{PM}_{2.5}$ and $\mathrm{PM}_{10}$ with correlation coefficients $\left(\mathrm{R}^{2}\right)$ of 0.8259 and 0.7934 , respectively.

Conclusion: Although the analysis and measurement revealed a reductive trend in the annual mean concentrations of PM2.5 and PM10, the measured AQI and EF values are still far from the standards of good quality and low pollution. Therefore, it is highly necessary to follow the air pollution protocols to control PM air pollution in Khuzestan Province.

\footnotetext{
* Corresponding Author: Nasrin Hassanzadeh, PhD.

Address: Department of Environment Sciences, Faculty of Natural Resources and Environment, Malayer University, Malayer, Iran. Phone: +98 (918) 9515729
}

E-mail: nasrinhassanzadeh@gmail.com 


\section{Introduction}

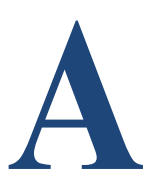

tmospheric pollution issues have become a severe environmental problem in urban areas of developing countries $[1,2]$ and many cities in developed countries [3]. The high concentration of air pollutants in urban areas is the most serious threat to human health and significantly impacts the ecological environment [4]. Among all atmospheric pollutants, particulates or Particulate Matters (PMs) are the most important compound in air pollution and have become a serious environmental risk globally $[5,6,7]$. $\mathrm{PM}$ is a composite of solid and or liquid organic and inorganic species originating from human activities or natural resources. They are suspended in the atmosphere and have different sizes $[8,9]$.

Atmospheric PMs are classified according to the aerodynamic diameter and include $\mathrm{PM}_{10}$ ( $\leq 10$ microns), $\mathrm{PM}_{2.5}$ ( $\leq 2.5$ microns), or $\mathrm{PM}_{1.0}$ ( $\leq 1.0$ microns) [10]. For urban air quality monitoring, the regarded particles usually are $\mathrm{PM}_{10}$ and $\mathrm{PM}_{2.5}$. These two particle fractions or ambient air particles are different in terms of the origin, lifetime, location of deposition in the body, various respiratory and cardiovascular diseases, and so on [11]. Because of a large number of natural and anthropogenic sources, PM events may have different origins. Anthropogenic sources of PM include combustion in mechanical and industrial processes, as well as, vehicle emissions but natural sources include volcanoes, fires, dust storms, and aerosolized sea salt [12].

Recently, PM pollution has been one of the most critical issues in expanding cities worldwide, especially in developing cities in Asia [12, 13]. Similarly, different cities of Iran are facing increasing urban air pollution of PM. These areas, like other fast-growing cities around the world, face expanding urbanization, growing energy consumption, high traffic congestion, and rapid industrial development. Finally, poor emissions control of these activities leads to continuous increase and thus exacerbates air pollution [14]. Besides, the findings of various studies indicate that the dust phenomenon considerably increases the levels of PM to values above the ambient air quality standards in many urban areas in the world $[15,16]$.

For this reason, nowadays, dust storms have increasingly become the most critical environmental problem that threatens the world. Lately, dust storms with regional and international origins in Iran have increased the PM concentration in the south, west, and southwest regions of this country and significantly increased PM levels above the standards set by the World Health Organization (WHO) $[17,18]$. In these areas, the Middle East Dust (MED) storms are a serious problem. They are considered the largest dust source affecting these regions, especially Khuzestan Province in the southwest region of Iran [19-21].

Different urban areas of Khuzestan Province have been exposed to high PM values due to their geographical and topographical conditions, expanding urbanization, MED storms, and rapid economic development, especially polluting industries such as oil, gas, petrochemical, and steel industries [19, 21, 22]. So, exposure to MED storms can be considered the most critical problem in the southwest regions of Iran [23]. In recent years, the different cities of Khuzestan Province have encountered several dust storms. So, the World Health Organization (WHO) defined these areas as the most contaminated regions globally in terms of the PM values $[17,18]$. Many epidemiological researchers have demonstrated that the increasing levels of ambient particle concentration in urban areas are responsible for various health problems [24]. In addition, PM can affect climate change [25] and atmospheric visibility [26]. Therefore, it is essential to study and accurately identify the spatiotemporal changes of air pollution (different sizes of PM), their associated sources, and their impacts. In this context, the findings of several studies have emphasized the significance of the ambient particulate matter and monitoring PM, especially $\mathrm{PM}_{10}$ and $\mathrm{PM}_{2.5}$ that are usually considered for urban air quality monitoring (Lithuania [27], India [10, 28] China [29, 30] Cameroon, Central Africa [2], Iran [31-33]). Furthermore, the Air Quality Index (AQI) has been considered as one of the essential tools used in analyzing and reporting air quality status in a particular area [4]. AQI has been used in many studies to determine the severity of pollution and report air quality levels [34-37]. In addition to using the AQI index, several studies have used the exceedance factor (EF) method introduced by the Central Pollution Control Board Central Pollution Control Board (CPCB) to assess the air quality of an area [38-40]

Therefore, our understanding of the spatial and annual variations of air pollutants in different urban areas of Khuzestan Province and reporting air quality levels can be helpful to support the implementation of air contamination control measures. The present study aims to investigate the spatial and temporal patterns of ambient air particles $\left(\mathrm{PM}_{2.5}\right.$ and $\left.\mathrm{PM}_{10}\right)$ in different urban regions of Khuzestan Province and assess the air quality in the investigated areas according to the fine $\left(\mathrm{PM}_{2.5}\right)$ and inhalable particles $\left(\mathrm{PM}_{10}\right)$ for the entire study period (2015-2019). 


\section{Materials and Methods}

\section{Study area characteristics}

In this descriptive and evaluative study of air quality, Khuzestan Province was selected as the study area. This Province is in the southwestern of Iran, covering an area of $63633 \mathrm{~km}^{2}$ and extending between north latitudes $29^{\circ}$ $57^{\prime}-33^{\circ} 00^{\prime}$ and east longitudes $47^{\circ} 40^{\prime}-50^{\circ} 33^{\prime}$. According to the latest statistics, the total population of this Province is approximately 4.7 million [41]. Of climate, most parts of the Province are dry (average rainfall is $266 \mathrm{~mm}$ ).

Different urban areas of Khuzestan Province, like other cities in developing states, are facing air contamination problems caused by anthropogenic and natural sources [42]. In this research, 6 monitoring sites in different cities of Khuzestan were selected to evaluate the air quality relating to the fine and coarse particles. In the metropolitan Ahvaz, the capital of Khuzestan, there are four air pollution monitoring stations. In the present research, two of these sites (Naderi and Edarekol) during the study period (2015-2019) were selected (because their data were available) as monitoring stations in this city. Each of the other cities in Khuzestan has only one monitoring station. In the present research, in addition to two monitoring stations in Ahwaz, some monitoring stations in Andimeshk, Shushtar, Shadegan, and Abadan cities were selected. Figure 1 shows the air quality monitoring stations of the Khuzestan Province.

\section{Data collection}

To carry out a comprehensive analysis of the PMs in Khuzestan, we obtained data of $\mathrm{PM}_{10}$ and $\mathrm{PM}_{25}$ concentrations from six air pollution-monitoring sites of the Province for 5 years (2015-2019) from the Environmental Protection Organization and Environmental Monitoring Center of Khuzestan Province. The average daily $\mathrm{PM}_{10}$ and $\mathrm{PM}_{2.5}$ concentrations were calculated from their hourly concentrations. The monthly average of $\mathrm{PM}_{10}$ and $\mathrm{PM}_{2.5}$ concentrations were calculated by daily mean concentrations for each of the 6 different sites. Then, average seasonal statistics were defined for spring (March-May), summer (June-August), fall (SeptemberNovember), and winter (December-February). Next, the annual mean concentrations of air pollutants for all stations were averaged using the corresponding daily mean concentrations. Finally, the data of all air pollution-monitoring sites were used to show air pollution situations as seasonal and annual $\mathrm{PM}_{10}$ and $\mathrm{PM}_{2.5}$ concentrations and their associated air quality indicators in different regions during the study period.

\section{Air quality assessment}

In the present study, two different methods were used to calculate the characterization of ambient air quality in selected urban areas of Khuzestan Province. These two methods are as follows.

\section{Average method}

The choice of the parameters for calculating AQI depends on various factors, including the objective of the index, the importance of the air quality parameters, and the availability of data [43]. In this research, the purpose of air quality assessment is to evaluate the ambient pollution level in terms of PMs and, therefore, $\mathrm{PM}_{2.5}$ and PM10 air pollutants were considered for the calculation of AQI because these two particles usually are used for urban air quality monitoring (Equation 1):

$$
\text { (1) } A Q I=\frac{1}{2}\left[\frac{P M_{2.5}}{s P M_{2.5}}+\frac{P M_{10}}{s P M_{10}}\right] \times 100
$$

, where applied to calculate the AQI and the standards of ambient air quality presented by the National Ambient Air Quality Standards (NAAQS) for $\mathrm{PM}_{2.5}$ and $\mathrm{PM}_{10}$, respectively. $\mathrm{PM}_{2.5}$ and $\mathrm{PM}_{10}$ exhibited the actual average calculated values at the sampling sites. After obtaining the monitored values, the concentrations of these particle matters are converted into AQI values. The AQI ranges are based on the average method, and the corresponding air quality condition categories and health effects are presented in Tables 1 and $2[44,45]$.

\section{Exceedance Factor (EF) and Average Exceedance} Factor (AEF)

In this article, the evaluation of the air quality situation has been done by using the Exceedance Factor (EF) technique presented by CPCB [46]. In EF, the annual average pollutant concentration is related to the specified standards. EF and AEF were calculated using Equations 2 and 3 , respectively $[43,47]$ :

$$
\text { (2) } E F=\frac{C_{\circ}}{C_{I}}
$$

where $\mathrm{Co}$ is the concentration of each particular pollutant and $\mathrm{Ci}$ is the NAAQS annual standard of respective pollutants Equation 3:

$$
\text { (3) } A E F=\frac{1}{N} \sum_{i=1}^{N} E F_{i}
$$

where EFi is the exceedance factor of the ith contaminant. $\mathrm{N}$ is the number of contaminants. An EF and AEF of 1 can be regarded as the threshold limit of a contaminant or a group of contaminants. According to EF, pollution level and air quality are classified into four categories [43, 48] 


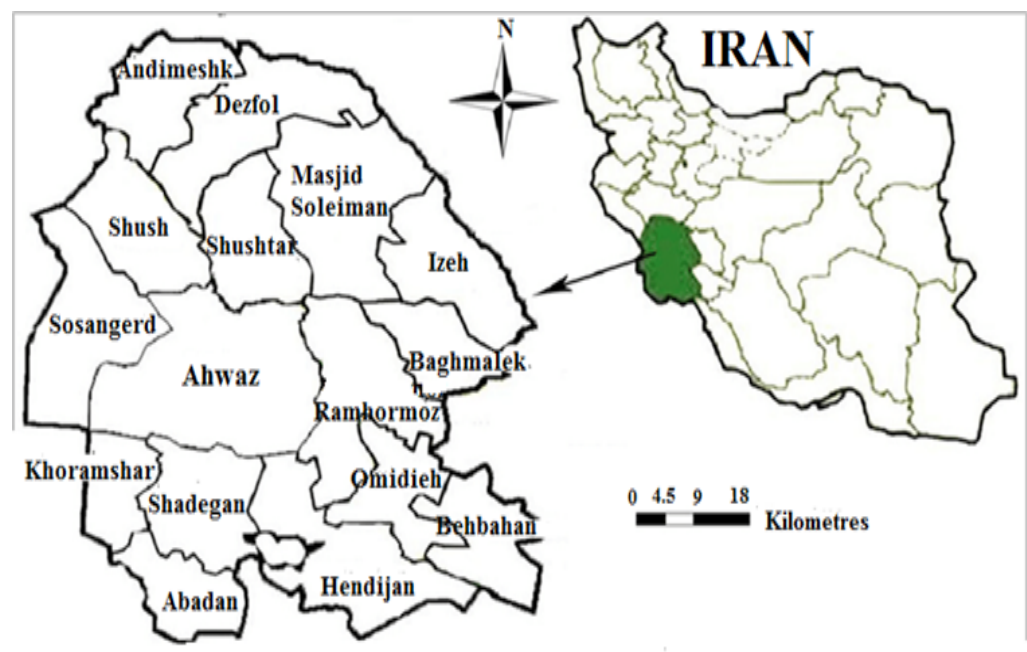

Khuzestan province

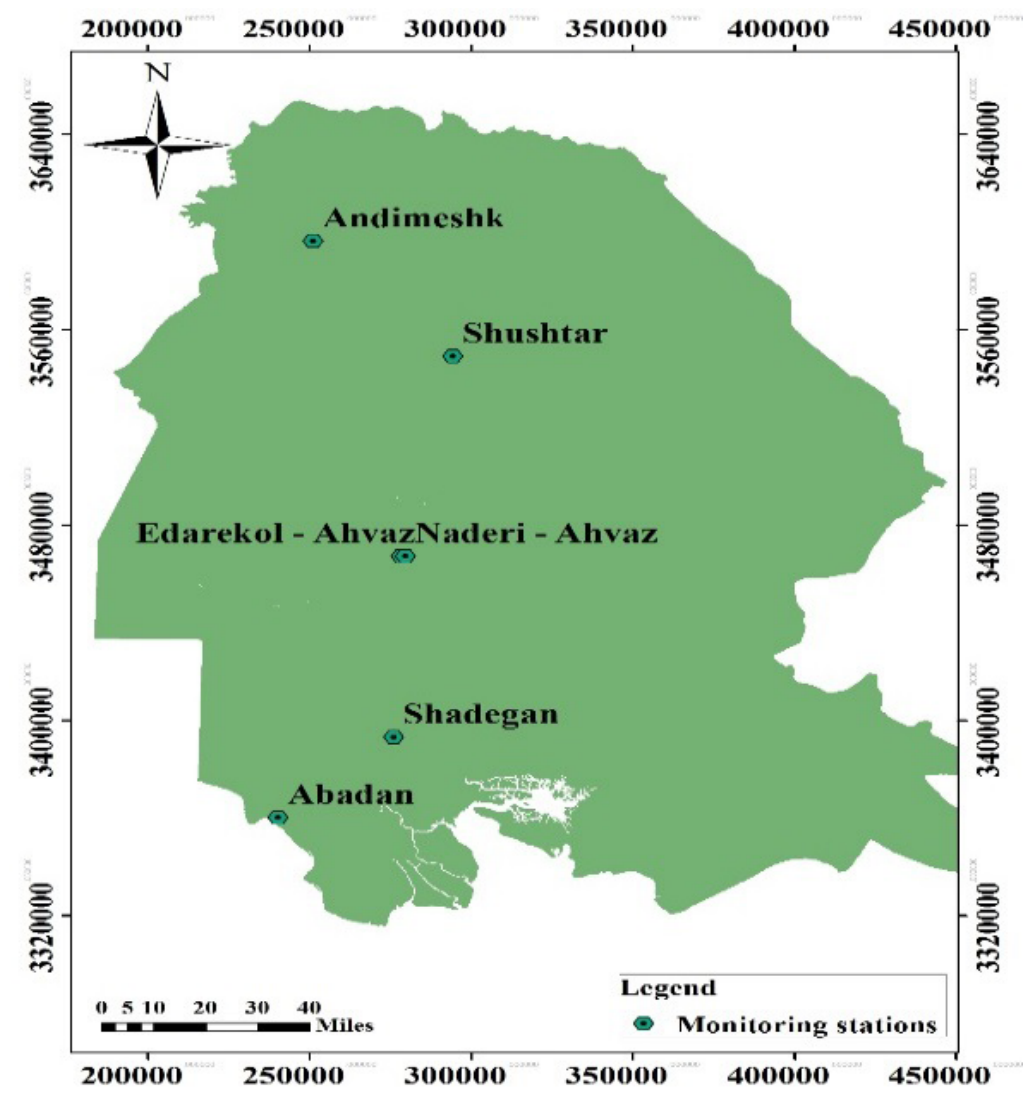

Figure 1. Locations of Khuzestan Province in Iran and the 6 monitoring sites in different cities of this province

\section{Statistical analyses}

Eventually, data were analyzed using SPSS v. 20. The Shapiro-Wilk test was applied to assess the normality of the data. A 1-way Analysis of Variance (ANOVA) and Duncan test were used to examine the significance of the differences in average air pollutants concentration $\left(\mathrm{PM}_{10}\right.$ and $\mathrm{PM}_{2.5}$ ) and $\mathrm{PM}_{2.5} / \mathrm{PM}_{10}$ ratio in the different studied stations, different seasons, and years of the study period The connections of $\mathrm{PM}_{2.5}$ and $\mathrm{PM}_{10}$ particulates, and Air Quality Index (AQI), were assessed using the linear regression model. The Spearman correlation test was used to rate the strength of the intra-seasonal and inter-seasonal correlation between PM concentrations. A P-value less than 0.05 was considered the statistical significance. Excel software was used for drawing tables and diagrams. 


\section{Results and Discussion}

Temporal Variations of the $\mathbf{P M}_{10^{\prime}} \mathbf{P M}_{2.5^{\prime}}$ and $\mathbf{P M}_{2.5}$ f $\mathrm{PM}_{10}$ Values

Figure 2 shows the comparison of temporal variation of annual mean concentrations of $\mathrm{PM}_{10}, \mathrm{PM}_{2.5}$, and $\mathrm{PM}_{2.5} / \mathrm{PM}_{10}$ ratio in different years of the study period. According to the ANOVA test, comparing the overall average concentrations of $\mathrm{PM}_{10}$ and $\mathrm{PM}_{25}$ between different years of the present study in Khuzestan Province showed significant differences between the annual mean concentrations of $\mathrm{PM}_{10}$ and $\mathrm{PM}_{2.5}$ in different years. For the entire study period, the highest annual values for $\mathrm{PM}_{10}$ were seen in 2017 and 2016, and for $\mathrm{PM}_{2.5}$ in 2017 and 2016, respectively. According to the ANOVA test results, there was no significant difference between the overall mean of $\mathrm{PM}_{2.5} / \mathrm{PM}_{10}$ ratio in different years of study (2015-2019). The Mean $\pm \mathrm{SD} \mathrm{PM} 2.5 / \mathrm{PM}_{10}$ ratio for the entire study period was $0.33 \pm 0.07$.

Levels of PMs significantly decreased in most monitoring stations from 2016 to 2019. In other words, during the last two years (2018 and 2019) of the present research, the annual mean concentrations of $\mathrm{PM}_{10}$ and $\mathrm{PM}_{2.5}$ declined compared to the previous years. The decrease in the levels of PMs can mainly be due to the environmental protection strategies and effective control measures by the Iranian
Environmental Organization in recent years [49]. In addition, the mass concentration of $\mathrm{PM}_{10}$ and $\mathrm{PM}_{2.5}$ in 2016 and 2017 were higher than other years of this study period. According to the studies conducted in Khuzestan Province, PMs (especially $\mathrm{PM}_{10}$ ) are produced chiefly by windblown dust caused by frequent dust storms and relatively fast winds $[5,50]$. So probably during this period, a large number of dust events have occurred. Based on the study by Momtazan et al. [5] on particulate matter in Abadan and Khorramshahr cities from 2014 to 2016, 152 dust events have occurred. The current study findings revealed that for the entire study period (2014-2016), the highest annual average $\mathrm{PM}_{10}$ concentrations occurred in Abadan and Khorramshahr in 2016. During these three years of study, the annual average PM10 concentration in these cities was considerably higher than the standard values recommended by the national standard for human health protection. Also, the high concentration of PMs in 2016 can be attributed to a persistent event in the southwestern region and some areas of western Iran from February 21-24, 2016. During this event, these areas were stormed by a very severe dust phenomenon. Following this event, according to the reports of the Environment Organization of Khuzestan Province from the two stations of Ahvaz and Abadan, the level of pollution in Ahvaz reached $9977 \mu \mathrm{g} /$ $\mathrm{m}^{3}$ (66 times the allowable limit) and in Abadan reached $10000 \mu \mathrm{g} / \mathrm{m}^{3}$ on the first day of the event (February 21) [51]. In another study by Daniali and Karimi [49], analysis

Table 1. Air Quality Index (AQI) values and the air quality condition categories [44]

\begin{tabular}{ccc}
\hline Air Quality Condition & AQI Values & SI. No \\
\hline Clean air & $0-25$ & 1 \\
\hline Light air pollution & $26-50$ & 2 \\
\hline Moderate air pollution & $51-75$ & 3 \\
\hline Heavy air pollution & $76-100$ & 4 \\
\hline Severe air pollution & $>100$ & 5 \\
\hline
\end{tabular}

Table 2. Air Quality Index (AQI) values and the level of health concerns [45]

\begin{tabular}{ccc}
\hline SI. No & AQI Values & Levels of Health Concern \\
\hline 1 & $0-50$ & Good \\
2 & $51-100$ & Moderate \\
3 & $101-150$ & Unhealthy For Sensitive Group \\
4 & $151-200$ & Unhealthy \\
5 & $>200$ & Hazardous \\
\hline
\end{tabular}




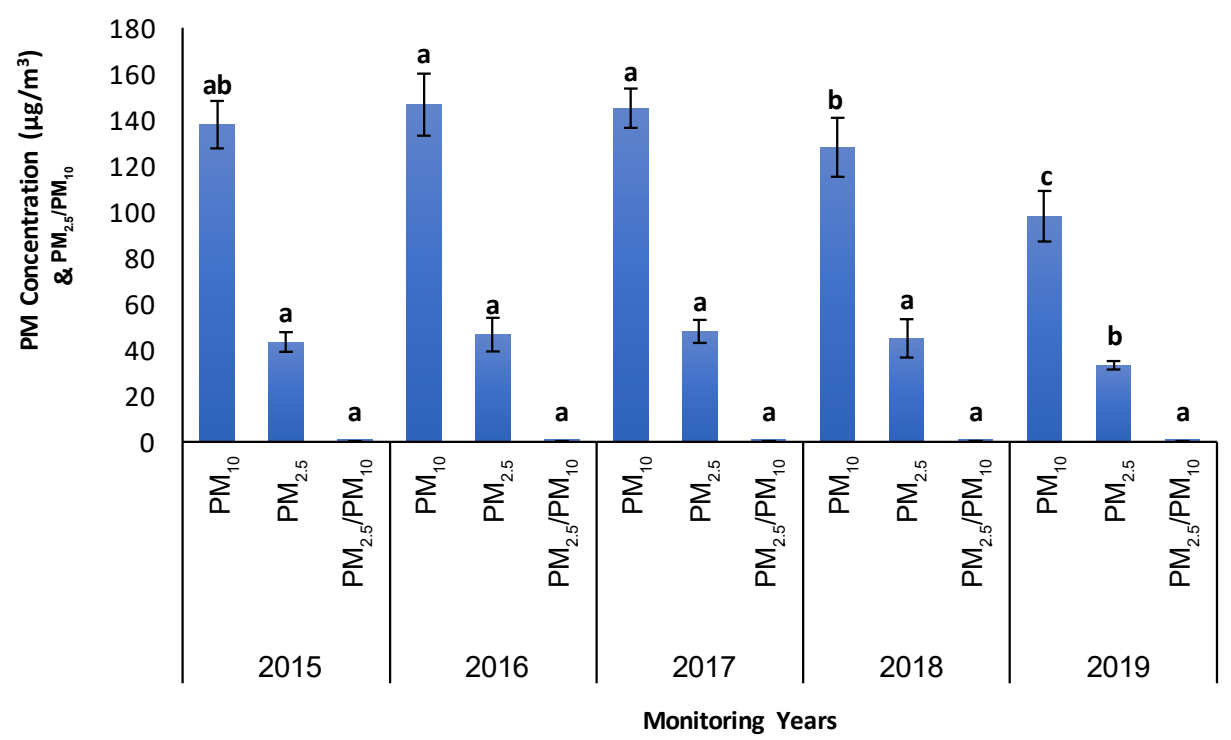

Figure 2. Temporal variations of average annual concentrations of $\mathrm{PM}_{2.5}$ and $\mathrm{PM}_{10}$ and $\mathrm{PM}_{2.5} / \mathrm{PM}_{10}$ ratio in 6 regions of khuzestan Province

of spatiotemporal of dust patterns over Khuzestan Province and regions in ancient Mesopotamia (2001-2017) showed that despite the fluctuations in the annual levels of the Aerosol Optical Depth (AOD), an increasing trend had been observed from 2001, peaking in 2008 and 2009. In this study, we observed a slight increase from 2013 to 2017 compared to the early years.

Spatial Variations of the $\mathbf{P M}_{10^{\prime}} \mathbf{P M}_{2.5^{\prime}}$ and $\mathbf{P M}_{2.5}$ $\mathrm{PM}_{10}$ Values

The spatial variation and distribution of annual mean concentrations of $\mathrm{PM}_{10}$ and $\mathrm{PM}_{2.5}$ and $\mathrm{PM}_{2.5} / \mathrm{PM}_{10}$ ratio between different stations during the study period are displayed in Figure 3. A comparison of the overall mean values of $\mathrm{PM}_{10}, \mathrm{PM}_{2.5}$, and $\mathrm{PM}_{2.5} / \mathrm{PM}_{10}$ ratio between different stations in Khuzestan Province showed significant differences between the annual average values in different stations $(\mathrm{P}<0.05)$ (Based on ANOVA test). A higher concentration of $\mathrm{PM}_{10}$ and $\mathrm{PM}_{2.5}$ was observed at Naderi station in Ahvaz and Abadan monitoring stations. These regions are two urban areas of Khuzestan Province with massive annual emissions of air pollutants from different resources. According to studies, the higher PM10 values in Ahvaz and Abadan resulted in more frequent MED events than in other cities [52]. Besides,

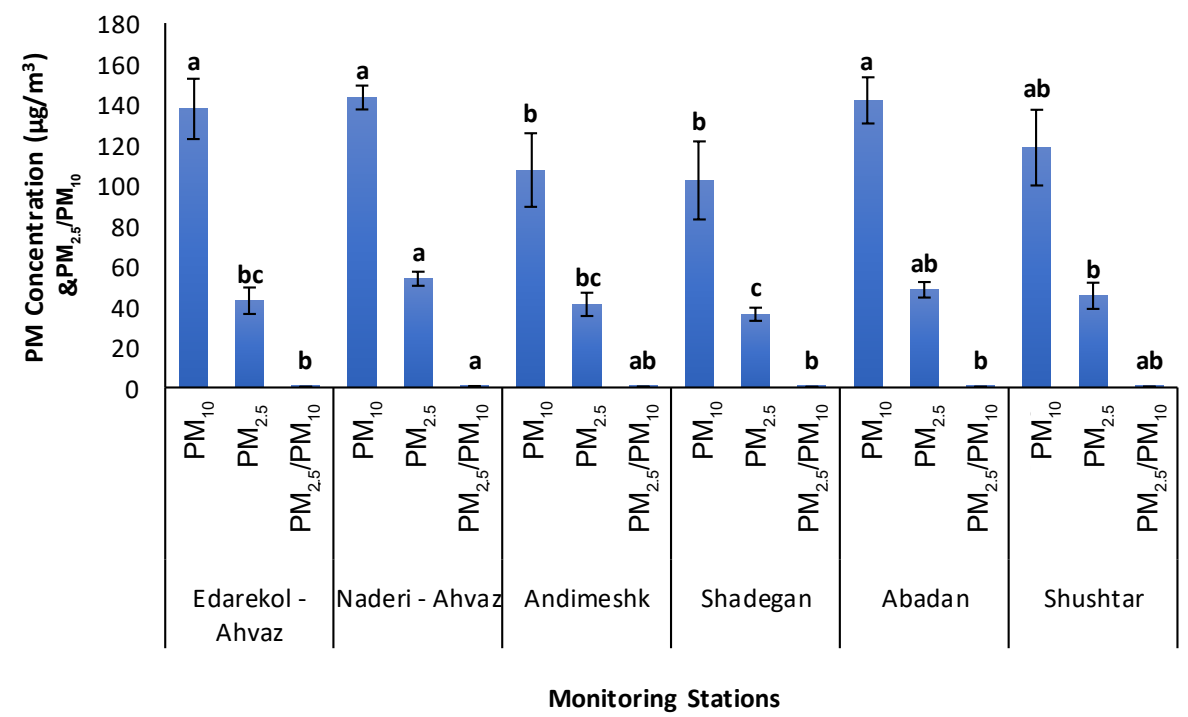

Figure 3. Spatial variation of annual mean concentrations of $\mathrm{PM}_{10^{\prime}} \mathrm{PM}_{2.5}$, and $\mathrm{PM}_{2.5} / \mathrm{PM}_{10}$ ratio in different stations for the entire study period 
these two cities are industrial, densely populated, and areas with high traffic $[5,53]$.

In Goudarzi et al. studies, the highest average concentration of particles was observed in the Naderi station of Ahvaz. These studies noted that this station is in the center of the Ahvaz and has increased traffic and population density; therefore, the PM concentration of this location was found higher than other stations [33].

In other studies on the particulate matter in Abadan City, results showed that a further increase in $\mathrm{PM}_{10}$ concentrations in Abadan could be because this city is usually exposed to dust storms blowing from neighboring arid regions like Iraq and Saudi Arabia and industrial activities [5, 52]. Similarly, according to Mehrabi et al. the maximum number of stormy days in the Abadan station is related to the geographical location of this station [54]. Furthermore, Jahanbakhsh et al. found that Abadan and Ahvaz cities have seen more dust storms than other cities in the western region because of their geographic location, being on the main routes of atmospheric systems, proximity to dust sources such as external dust centers and proximity to dried-up wetlands and their physicalnatural characteristics [55]. The lowest concentration of $\mathrm{PM}_{10}$ and $\mathrm{PM}_{2.5}$ was seen in the Andimeshk and Shadegan monitoring stations. This finding could be due to low traffic and population density and lack of industrial activity in these areas [56].

The average concentration of $\mathrm{PM}_{10}$ and $\mathrm{PM}_{2.5}$ at all stations throughout the study period is substantially higher than the annual mean standards determined by the NAAQS $\left(\mathrm{PM}_{2.5}=40 \mu \mathrm{g} / \mathrm{m}^{3}\right.$ and $\left.\mathrm{PM}_{10}=100 \mu \mathrm{g} / \mathrm{m}^{3}\right)$ and the United States Environmental Protection Agency (USEPA) $\left(\mathrm{PM}_{2.5}=15 \mu \mathrm{g} / \mathrm{m}^{3}\right.$ and $\left.\mathrm{PM}_{10}=50 \mu \mathrm{g} / \mathrm{m}^{3}\right)$.

Because different PM sizes originate from various sources, the PM ratios can be used as an indicator to identify their sources [57]. A lower value of $\mathrm{PM}_{2.5} / \mathrm{PM}_{10}$ ratio means that natural sources and dust events have a comparatively significant contribution to the production of PM [58]. A higher ratio of $\mathrm{PM}_{2.5} / \mathrm{PM}_{10}$ indicates a significant contribution of $\mathrm{PM}_{2.5}$, which is generally attributed to primary contamination by anthropogenic activities [57]. In this research, the $\mathrm{PM}_{2.5} / \mathrm{PM}_{10}$ ratio in the different stations showed variability from 0.11 to 0.74 , and the Mean \pm SD $\mathrm{PM}_{2.5} / \mathrm{PM}_{10}$ ratio over the 5 study years was $0.33 \pm 0.07$. In Asia, the ratio is generally less than 0.5 , indicating higher coarse particle masses [59]. Furthermore, the lower values of the $\mathrm{PM}_{2.5} / \mathrm{PM}_{10}$ ratio indicate air pollution caused by natural resources and dust events [59].
In the southwest of Iran, dust storms in the Middle East region are one of the reasons that can lead to this result [22]. This phenomenon is a serious problem and is considered the largest dust particle source and is responsible for significant increases of ambient PMs (especially $\mathrm{PM}_{10}$ ) concentrations in the southwest region of Iran, especially Khuzestan Province [20, 21, 33]. So, it is clear that the rise in $\mathrm{PM}_{10}$ due to local dust emissions and regional dust transfer significantly contributes to higher $\mathrm{PM}_{10}$ concentrations and, therefore, lower $\mathrm{PM}_{2.5} /$ $\mathrm{PM}_{10}$ values [59]. The studies carried out by $\mathrm{Li}$ et al. in China [13] and Nducol et al. in Africa [2] to assess the particulate matter pollution in the urban areas revealed similar results. The spatial distribution of $\mathrm{PM}_{10}, \mathrm{PM}_{2.5}$, and $\mathrm{PM}_{2.5} / \mathrm{PM}_{10}$ ratio between different stations for the entire study period is shown in Figure 4.

\section{Seasonal Variation of $\mathbf{P M}_{10^{\prime}} \mathbf{P M}_{2.5^{\prime}}$ and $\mathbf{P M}_{2.5} / \mathbf{P M}_{10}$ Ratio Values}

The seasonal mean values of $\mathrm{PM}_{2.5}, \mathrm{PM}_{10}$, and $\mathrm{PM}_{2.5} /$ $\mathrm{PM}_{10}$ ratio during the studied seasons are presented in Figure 5. According to 1-way ANOVA results, significant differences $(\mathrm{P}<0.05)$ were observed between the studied seasons regarding the $\mathrm{PM}_{10}$ and $\mathrm{PM}_{2.5}$ values and $\mathrm{PM}_{2.5} /$ $\mathrm{PM}_{10}$ ratio. This figure reveals that the mean concentration of $\mathrm{PM}_{10}$ and $\mathrm{PM}_{2.5}$ are highest in summer and lowest in the winter season, while the $\mathrm{PM}_{2.5} \mathrm{PM}_{10}$ ratio was higher in winter and autumn than in summer and spring.

These seasonal changes are attributed to sources of pollution and meteorological conditions. As mentioned, the highest amount of PM concentration during the study period was found in the summer season. This increase mainly occurred because during this time, especially in the late spring and the beginning of summer, the precipitation is very low, and evaporation is very high. So the soil is very dry, which causes wind erosion and the transport of suspended particles of soil over long distances [41]. Also, the higher concentrations of $\mathrm{PM}_{10}$ in summer can be associated with the higher numbers of dust events in this season.

The results are almost consistent with other results regarding $\mathrm{PM}_{10}$ assessment in Iranian cities. Masoudi et al. found that the seasonal concentration of the PM10 had the highest values in summer and the lowest in winter [41]. The results in this part are consistent with other results regarding $\mathrm{PM}_{10}$ assessment in Iranian cities of Kermanshah [60], Ilam [61], and Bukan in West Azerbaijan Province [62]. In these studies, the reasons for the increase in PM concentration in summer compared to winter were attributed to frequent dust entrance originating from neighboring countries, humidity reduc- 

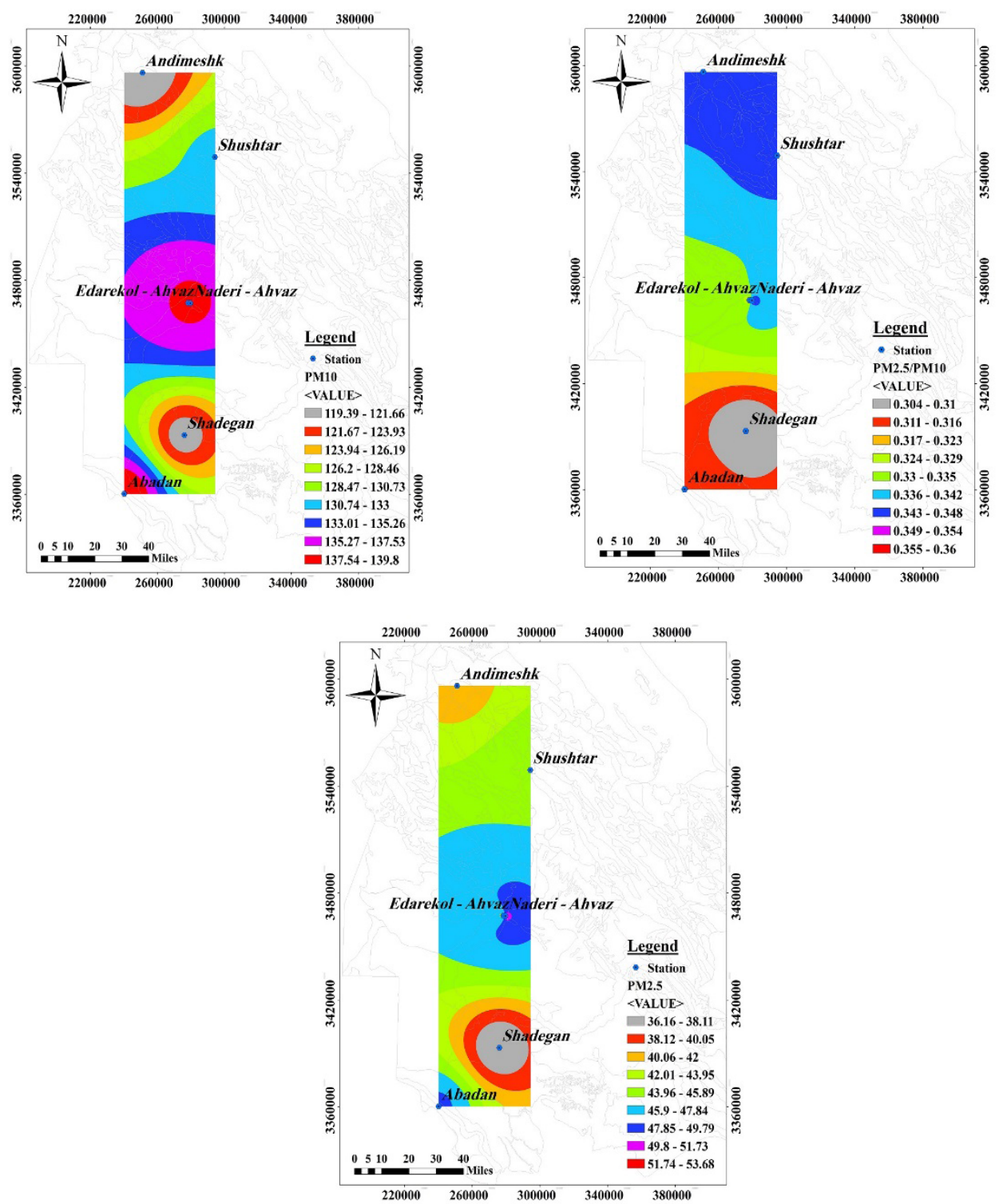

Figure 4. Spatial distribution of annual mean concentrations of $\mathrm{PM}_{10^{\prime}} \mathrm{PM}_{2.5^{\prime}}$ and $\mathrm{PM}_{2.5} / \mathrm{PM}_{10}$ Ratio in different stations for the entire study period

tion, drought, and the temperature rising, as well as wind speed and direction. In studies performed by Tiwari et al. [10] and Gautam and Brema [28], the higher PM concentration in summer was attributed to dust storm activities this season.

In contrast to these findings, Pandey et al. [24], Trivedi et al. [63], Xu et al. [64], and Kuerban et al. [29] reported that the largest PM concentration was observed in winter and the lowest in summer. The highest values of the $\mathrm{PM}_{2.5} / \mathrm{PM}_{10}$ ratio were observed in cold seasons (autumn and winter). In another similar study, Xu et al. [65] found that the highest $\mathrm{PM}_{2.5} / \mathrm{PM}_{10}$ value for winter with 0.75 was $20 \%$ more than the minimum ratio of 0.55 obtained for summer in the Wuhan urban area (Central
China). Similar findings have been reported by Tiwari et al. whose seasonal $\mathrm{PM}_{2.5} / \mathrm{PM}_{10}$ ratio calculations showed that the largest value was observed in post-monsoon (0.63) and winter (0.62) [10]. The increase in fine particle emissions and, therefore, this ratio increase in cold seasons could be due to increasing fuel consumption for domestic and industrial heating in these seasons [66].

\section{Relationship Between $\mathrm{PM}_{2.5}$ and $\mathrm{PM}_{10}$}

To estimate the relationship between various sizes of particulate matter and the impact of seasonal changes on their relationships, the analysis of the linear regression model for $\mathrm{PM}_{2.5}$ and $\mathrm{PM}_{10}$ was performed. Figure 6 shows the scatter diagrams of the linear regression of $\mathrm{PM}_{2.5}$ 


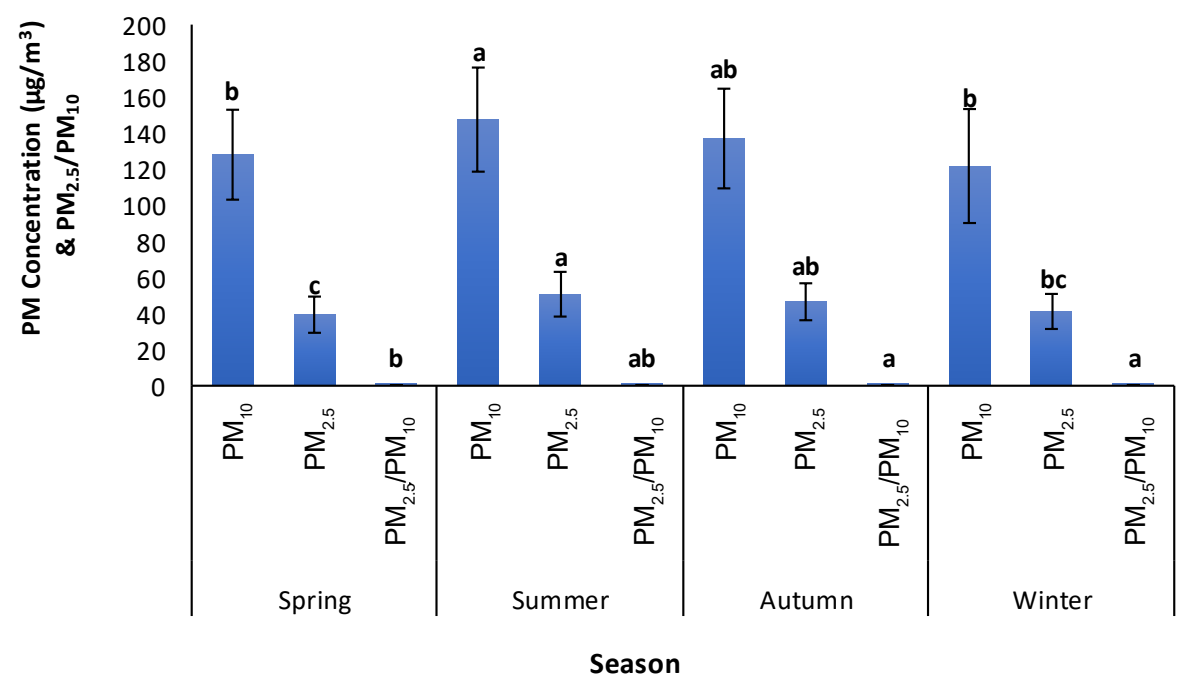

Figure 5. Influence of seasonal variation on $\mathrm{PM}_{10}$ and $\mathrm{PM}_{2.5}$ concentration $\left(\mu \mathrm{g} / \mathrm{m}^{3}\right)$ and $\mathrm{PM}_{2.5} / \mathrm{PM}_{10}$ ratio at all regions of Khuzestan Province, 2015-2019

Different letters in each column indicate a significant difference between the seasons in terms of mean values of $\mathrm{PM}_{\text {and }} \mathrm{PM}_{25} / \mathrm{PM}_{10}$ ratio.

against $\mathrm{PM}_{10}$ concentration in various seasons. According to Figure 5, the correlation between $\mathrm{PM}_{2.5}$ and $\mathrm{PM}_{10}$ in different seasons is significant, with the correlation coefficients (R) of 0.66 in spring, 0.61 in summer, 0.56 in autumn, and 0.82 in winter. The correlation between both parameters $\left(\mathrm{PM}_{10}\right.$ and $\left.\mathrm{PM}_{2.5}\right)$ in each season can be characterized as shown below.

Spring, Figure 6-A: In this season, the connection between the particles with different sizes $\left(\mathrm{PM}_{10}\right.$ and $\left.\mathrm{PM}_{2.5}\right)$ is moderate $(0.5<\mathrm{R}<0.7)$, and only $40 \%\left(\mathrm{R}^{2}=0.4\right)$ of $\mathrm{PM}_{2.5}$ is predictable using the equation.

Summer, Figure 6-B: In this season, similar to the spring season, there is a moderate relationship between the two pollutants $(0.5<\mathrm{R}<0.7)$, and $37 \%\left(\mathrm{R}^{2}=37\right)$ of particulate matter concentrations are acquired by equation.

Autumn, Figure 6-C: In this season, we also observed a moderate connection between the two pollutants $(0.5<\mathrm{R}<0.7)$, and $30 \%\left(\mathrm{R}^{2}=0.3\right)$ of contaminant concentrations were found by the equation .

Winter, Figure 6-D: In this season, there was a reasonably strong connection since $\mathrm{R}^{2}>0.6$. The linear regression showed that $68 \%$ of concentration levels follow.

The regression equations obtained in this section indicate that in all seasons of the study period, the $\mathrm{PM}_{10}$ concentration increases with increasing $\mathrm{PM}_{2.5}$ concentration. The highest correlation (0.82) was obtained between $\mathrm{PM}_{10}$ and $\mathrm{PM}_{2.5}$ for the winter season, followed by $0.66,0.61$, and 0.51 for spring, summer, and autumn, respectively. These findings indicate that during these four seasons, especially the winter season, either the two $\mathrm{PM}$ sizes $\left(\mathrm{PM}_{10}\right.$ and $\left.\mathrm{PM}_{2.5}\right)$ have the same resources or are generated by different sources at the same time and place [63]. Similarly, in many other studies, the correlations between different particle sizes have been attributed to common and the same emission resources and occasionally common meteorological influences on concentrations [67-69]. So in the present research, the more significant association between $\mathrm{PM}_{2.5}$ and $\mathrm{PM}_{10}$ in the winter than other seasons can be due to emissions of these pollutants from similar sources in this season $[2,63]$. On the other hand, less correlation between $\mathrm{PM}_{10}$ and $\mathrm{PM}_{2.5}$ in other seasons may be because, in these seasons, $\mathrm{PM}_{10}$ originates more from dust storms and $\mathrm{PM}_{2.5}$ from industrial and transportation activities.

Spatial and temporal variation characteristics of aqi and the corresponding air quality condition

Figure 7 displays the spatial and temporal variations of AQI and the corresponding air quality condition based on the average method at the different locations over the 5 years (2015 to 2019). Comparing the spatial and temporal variations of the AQI (according to the ANOVA test) showed significant differences between different years of the study period $(\mathrm{P}<0.05)$ (Figure 8$)$. However, AQI variations were not significantly different between different cities $(\mathrm{P}>0.05)$. Although the highest mean of AQI was observed in Naderi and Abadan and the lowest in Andimeshk and Shadegan stations, their difference 

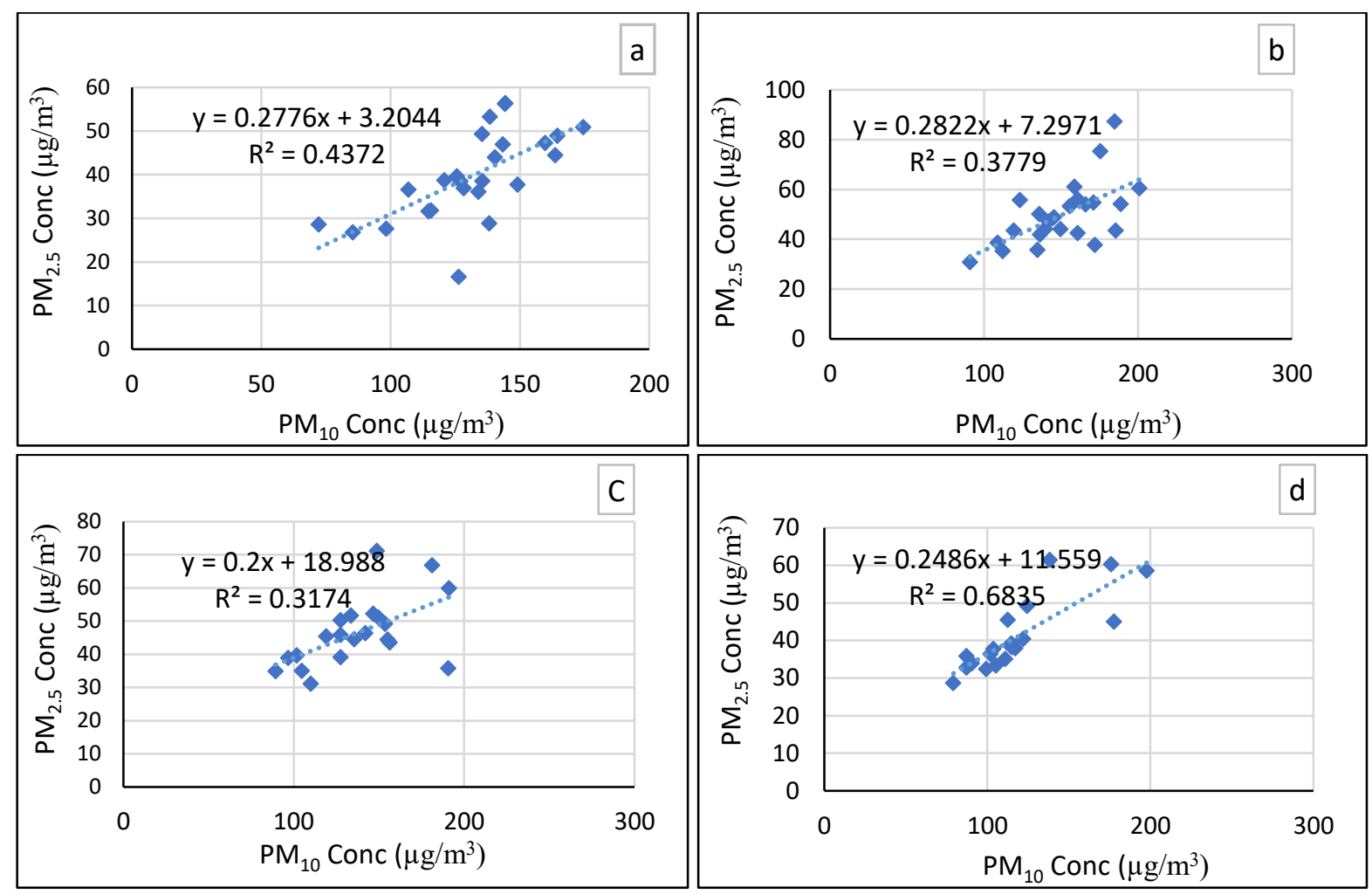

Figure 6. Linear regression between $\mathrm{PM}_{2.5}$ and $\mathrm{PM}_{10}$ during different seasons

$\mathrm{A}=$ Spring; $\mathrm{B}=$ Summer; $\mathrm{C}=$ Autumn; and $\mathrm{D}=$ Winter.

was not significant. According to the results of checking the air quality condition in Figure 6, all regions experienced severe air pollution during the study period. Only in 2019, Naderi, Ahvaz, and Abadan areas show moderate to heavy air pollution status.

The trend analysis of the annual average AQI in different regions of Khuzestan Province shows that the AQI in this province is high. During the study period from 2015 to 2019 , the AQI was higher than 100 , indicating severe air pollution in this province. Specifically, during these 5 years of study, air pollution was significant in 2016 and 2017, with a Mean \pm SD AQI of $180.42 \pm 17.91$ and $180.85 \pm 11.52$, respectively. In later years (2018-2019), the amount of AQI has decreased; however, the value of AQI in the past two years is still more than the standard to achieve excellent quality, where $A Q I<50$. This decrease can be attributed to the environmental protection measures such as controls on emissions from various industries, fossil fuel consumption, and other actions in recent years in this province.

The highest Mean \pm SD of AQI was observed in Naderi (176.53 \pm 24.88$)$ and Abadan (173.98 \pm 24.88$)$. Ahvaz and Abadan cities face major air pollution issues due to the high population density and many vehicles and indus- tries compared with other study regions. Dadhich et al. [4] conducted a study on temporal and spatial changes in the air quality of Jaipur City (India) from 2004 to 2015 They found out that AQI calculation indicates that the urban areas of Kishanpole, Hawa Mahal, faced severe air pollution problems due to the high density of population and motor vehicles. Moreover, Lin and Zhu [70] examined the affecting factors on air quality. Their results confirmed that the factors such as population density, energy consumption, and industrialization could deteriorate air quality in China. In addition, the results of a study performed by Dai and Yi in the assessment of spatial and temporal variations and affecting factors on air quality in Chinese cities indicated that AQI could also be affected by topographic, meteorological, and socioeconomic factors [71].

Spatial and temporal variation characteristics of $A Q I$ and the corresponding health effects

The annual variation of AQI and the corresponding health effects during the study period (2015-2019) for all regions are summarized in Figure 8. Assessment of the ambient air quality levels regarding $\mathrm{PM}_{10}$ and $\mathrm{PM}_{2.5}$ and the related health impacts indicates that the AQI values were in the unhealthy category at different stations from 


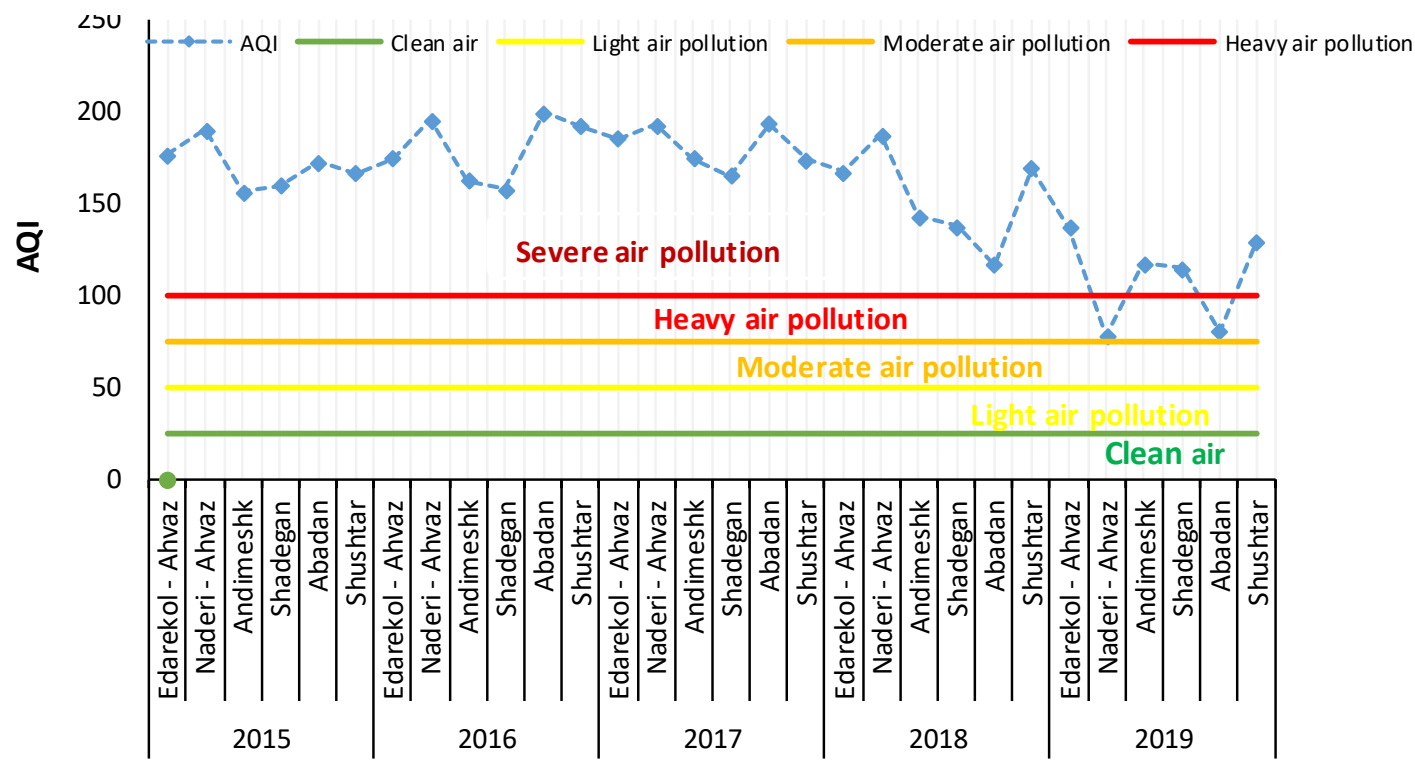

Figure 7. Annual variations of air quality index and the corresponding air quality condition based on average method at the different regions of Khuzestan Province, 2015-2019

2015 to 2017. In 2018 and 2019, the AQI categories regarding PM were frequently "unhealthy" to "unhealthy for sensitive groups" and "moderate" to "unhealthy for sensitive groups", respectively, at the different locations. Calculating the AQI levels and assessment of the corresponding health effects in different regions from 2015 to 2019 indicates that although air quality improves from 2015 to 2019, the values of AQI are still more than the standard to achieve excellent quality (AQI $<50)$. In 2017, Dastoorpoor et al. [72] reported that according to the AQI in relation to PM10 in Ahvaz during the study period, only in $2.1 \%$ of the days, the Ahvaz air was clean $(0-50)$. Also, in 15.7, 26.5, 20.8, 17.1, and $10.7 \%$ of the days, the air quality was "moderate", "unhealthy for sensitive groups", "unhealthy", "very unhealthy", and "hazardous", respectively. In this study, based on the $\mathrm{AQI}$ and the corresponding health effects, on most days, the air quality was "unhealthy" and "unhealthy for sensitive groups", which is almost consistent with the present research findings. Therefore, the computed AQI values clearly show the alarming air quality in the urban regions of Khuzestan Province, especially Ahvaz and Abadan.

According to Figure 9, the spatial variation of AQI values at different selected locations during 2015-2019 can be observed. Based on these figures, significant annual variation could be easily identified.
Analysis of Correlation Between AQI, $\mathrm{PM}_{25^{\prime}}$ and $\mathrm{PM}_{10}$

To further examine the relationship between AQI and $\mathrm{PM}_{2.5}$ and $\mathrm{PM}_{10}$, their linear relations were examined. Figure 10 illustrates the relationship between PM concentrations and AQI. As seen in Figure 10-A and Figure 10-B, $\mathrm{AQI}$ has a significant positive relationship with $\mathrm{PM}_{2.5}$ and $\mathrm{PM} 10\left(\mathrm{R}^{2}=0.8259, \mathrm{P}<0.01 ; \mathrm{R}^{2}=0.7934, \mathrm{P}<0.01\right)$. In general, the relationship between $\mathrm{AQI}$ and $\mathrm{PM}_{2.5}$ was slightly better. The relationship between AQI and PM concentrations illustrated that the fine particle contamination of different cities of Khuzestan had significant air quality impacts. Similarly, Wang et al. [73] evaluated the AQI variation trend and its possible relationship with $\mathrm{PM}_{2.5}$ and $\mathrm{PM}_{10}$ in the BeijingTianjin Hebei area from July 2015 to 2018. According to their findings, a significant positive correlation can be seen between $\mathrm{AQI}$ and $\mathrm{PM}_{2.5}$ and PM10 $\left(\mathrm{R}^{2}\right.$ was 0.8225 and 0.7749, respectively, $\mathrm{P}<0.01)$ and $\mathrm{PMs}\left(\mathrm{PM}_{10}\right.$ and $\left.\mathrm{PM}_{2.5}\right)$ showed a larger impact on the air quality of Beijing-TianjinHebei. Furthermore, in a research conducted by Zhao et al. [57], the Spearman correlation analysis revealed a significant positive correlation between the $\mathrm{PM}_{2.5} / \mathrm{PM}_{10}$ ratio and the $\mathrm{AQI}$ value, and $\mathrm{PM}_{2.5}$ contributed to more reduction in air quality than $\mathrm{PM}_{10}$ (especially in winter).

Spatial and temporal variation characteristics of Exceedance Factor (EF)

Spatial-temporal changes of EF of $\mathrm{PM}_{10}$ and $\mathrm{PM}_{2.5}$ at the different regions of Khuzestan Province during the 


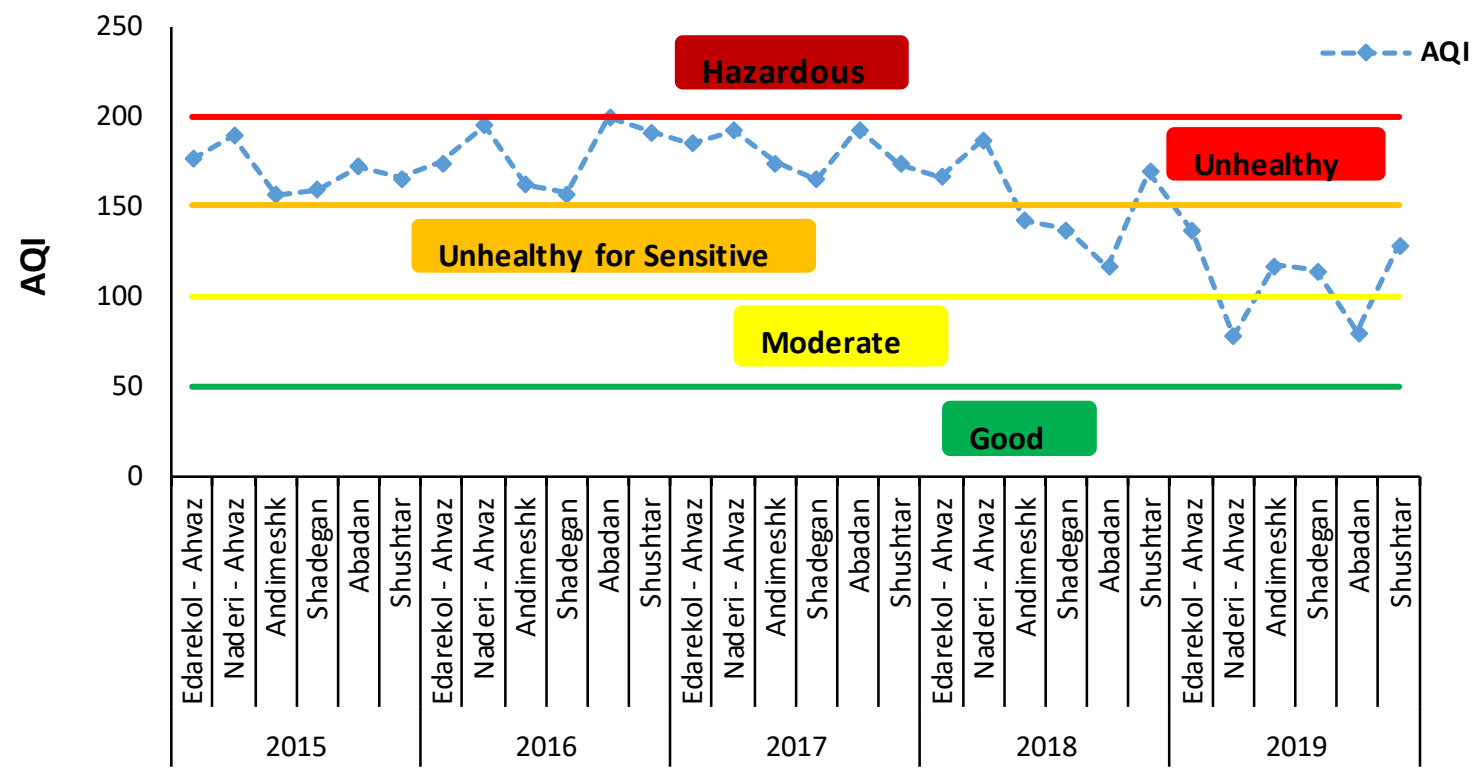

Figure 8. Annual variations of air quality index and the corresponding health effects based on average method at different regions of Khuzestan Province, 2015-2019

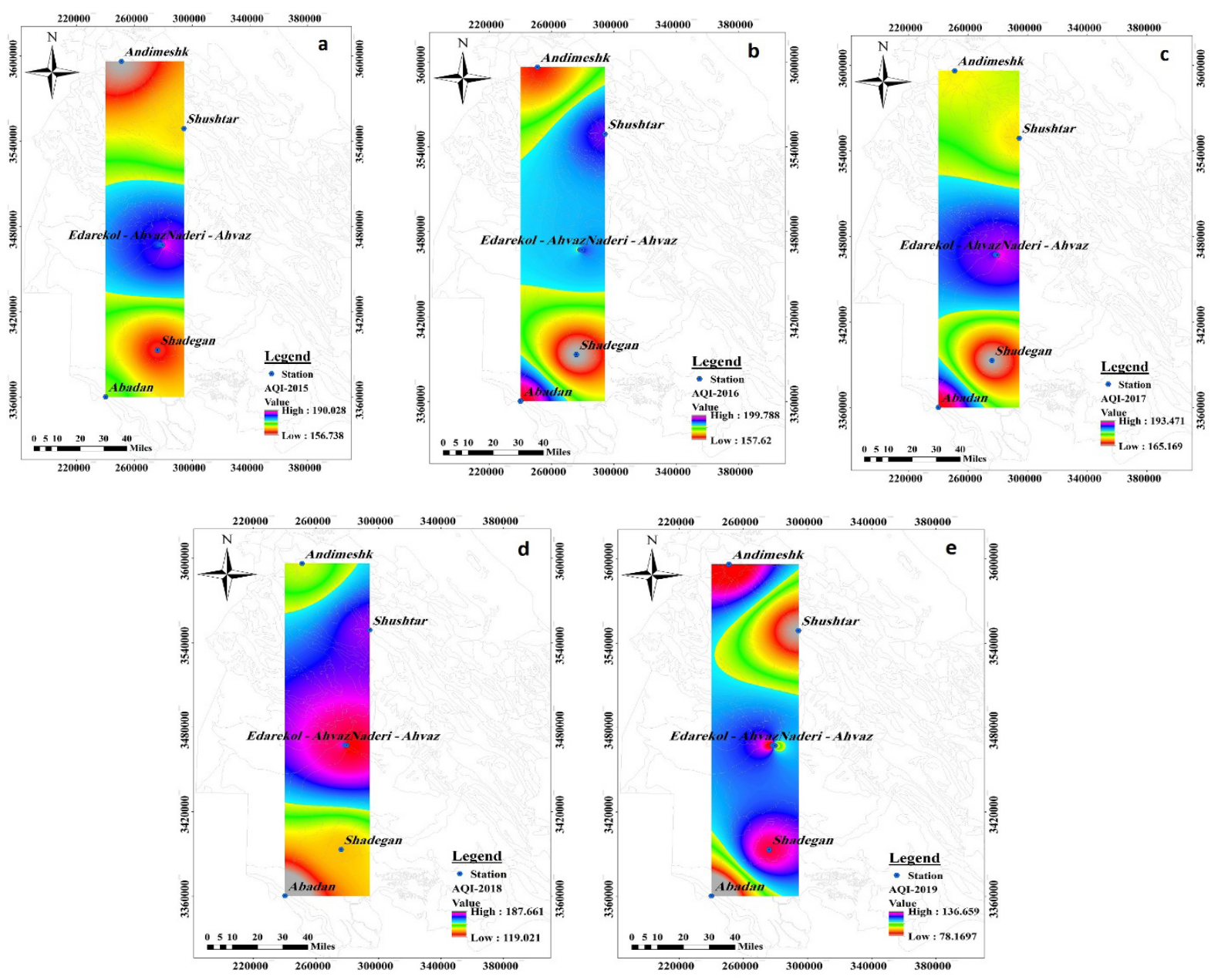

Figure 9. Spatial distribution of the Air Quality Index (AQI) in 6 regions of Khuzestan Province A: 2015; B: 2016; C: 2017; D: 2018; and E: 2019. 


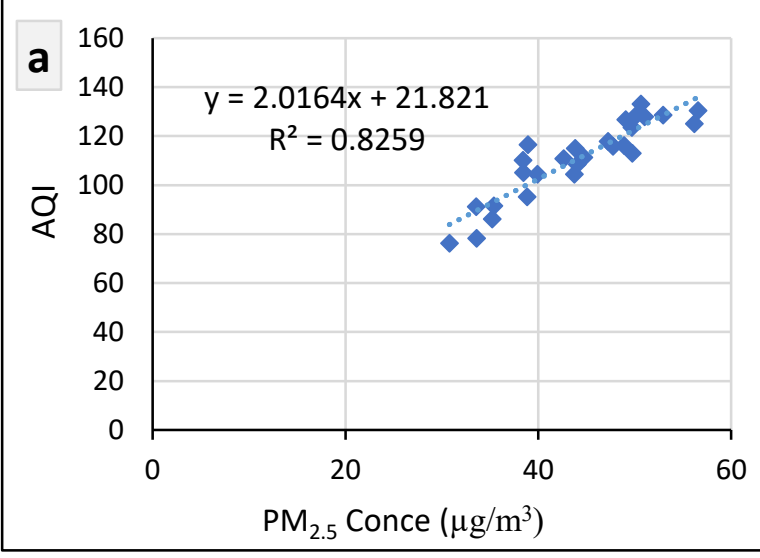

Figure 10. Linear fitting of $\mathrm{AQI}$ with $\mathrm{PM}_{2.5}$ and $\mathrm{PM}_{10}$

study period (2015 - 2019) are shown in Figure 11. The results showed that the EF of $\mathrm{PM}_{10}$ in the different years of the study period was between 1.51 and 2.73, and there was a significant difference between the years in relation to $\mathrm{EF}$ of $\mathrm{PM}_{10}(\mathrm{P}=0.001)$. But in terms of spatial variation of $\mathrm{EF}\left(\mathrm{PM}_{10}\right)$, no significant difference was found between different stations $(\mathrm{P}>0.05)$.

The EF values of $\mathrm{PM}_{2.5}$ for all study years ranged from 0.77 to 1.41. A significant difference in $\mathrm{EF}\left(\mathrm{PM}_{2.5}\right)$ was seen between the stations $(\mathrm{P}<0.05)$, with the highest concentrations in the Naderi station in Ahvaz and Abadan. Comparing the temporal variations of $\mathrm{EF}\left(\mathrm{PM}_{2.5}\right)$ showed a significant difference in $\mathrm{EF}$ values of $\mathrm{PM}_{2.5}$ among the

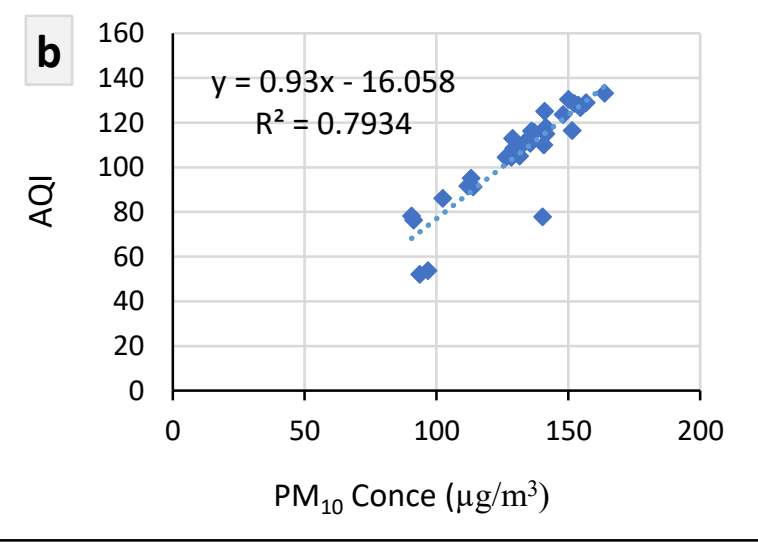

different years of the study period $(\mathrm{P}<0.05)$, with the highest in 2017 and 2016 and lowest in 2019.

Comparison of air quality categories based on $\mathrm{EF}$ of PM pollutants at all sampling stations over the entire study period revealed that the $\mathrm{EF}$ of $\mathrm{PM}_{10}$ was higher than the factors defined by the CPCB for critically polluted regions $(\mathrm{EF}>1.5)$. Still, the observed $\mathrm{EF}$ of $\mathrm{PM}_{2.5}$ pollutant varied from the highest pollution $(1.0 \leq \mathrm{EF}<1.5)$ to moderate pollution $(0.5 \leq \mathrm{EF}<1.0)$ (Figure 12). The results of this section indicate that these pollutants (spatially $\mathrm{PM}_{10}$ ) are responsible for high or critical pollution, which considerably leads to the deterioration of air quality in all studied regions. Similarly, Robert and Pirro [74] assessed the ambient air quality status in ma-

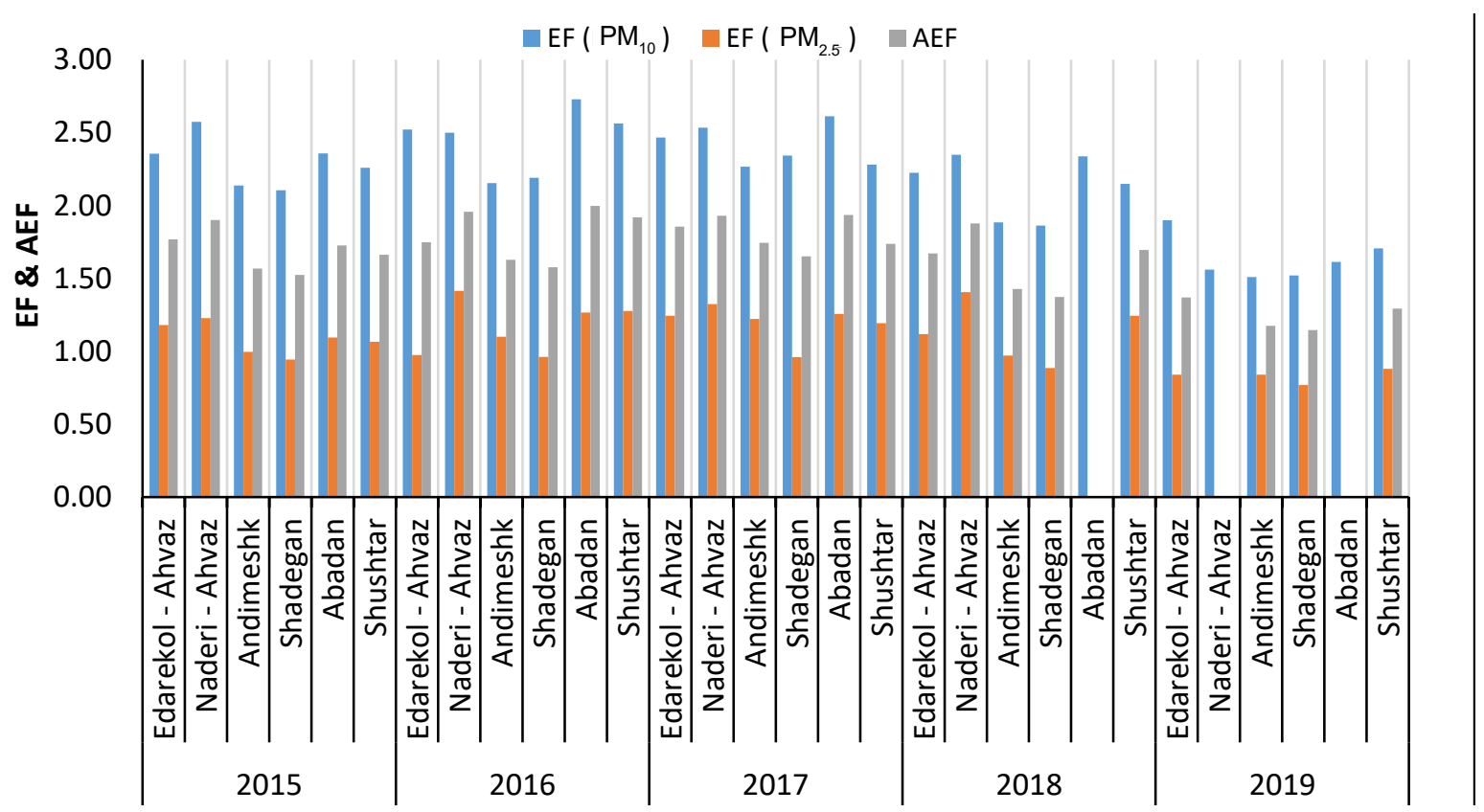

Figure 11. Annual trends of urban ambient air quality based on exceedance factor method at different regions of Khuzestan Province, 2015-2019 


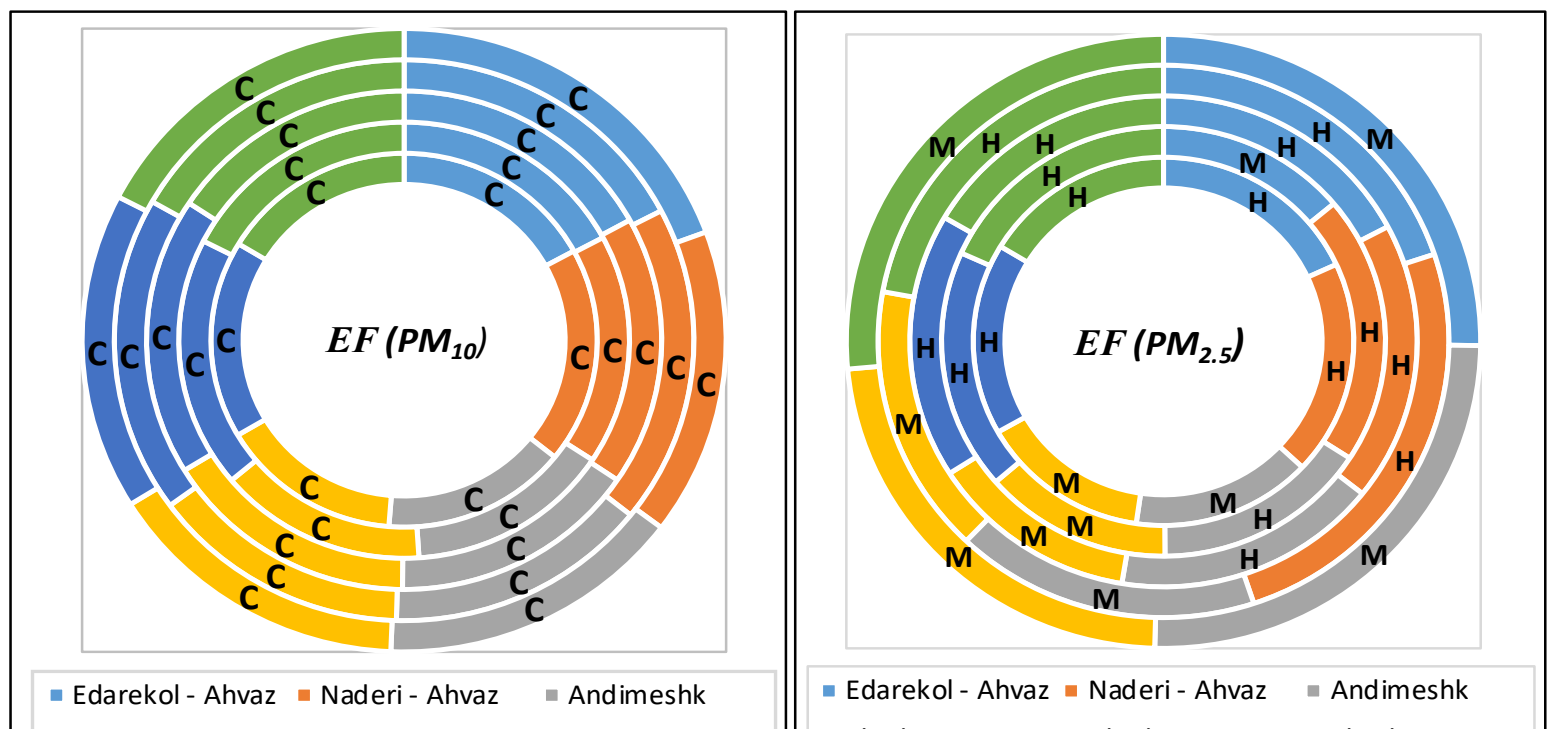

Figure 12. Annual variations of air quality categories based on EF at different regions, 2015-2019

EF categories: $\mathrm{L}=$ Low Pollution; $\mathrm{M}=$ Moderate Pollution; $\mathrm{H}=$ High Pollution; $\mathrm{C}=$ Critical.

jor cities of Albania based on EF. They found that the $\mathrm{PM}_{10}$ and Suspended Particulate Matter (SPM) are the most important polluting factors which must be carefully examined. In addition, Banerjee and Srivastava [43] reported that the EF values for certain pollutants showed that respirable suspended particulate matter (RPM) with an $\mathrm{EF}$ value of 1.14 is the main contaminant responsible for the deteriorating air quality at Integrated Industrial Estate-Pantnagar (IIE-Pantnagar) and SPM with an EF of 0.78 is responsible for creating moderate contamination. According to the results, the mean values of AEF at all regions of Khuzestan during the study period were higher than 1 , and the AEF value of 1 is the threshold limit of a contaminant or a group of contaminants.

\section{Conclusion}

This investigation was performed to understand the spatiotemporal characteristics of air quality and the PM pollutants that affect the AQI in different cities of Khuzestan Province in recent years (2015-2019). Although the annual mean concentrations of $\mathrm{PM}_{2.5}$ and $\mathrm{PM}_{10}$ indicate a gradual decline trend in the PM pollutants, the obtained $\mathrm{AQI}$ and $\mathrm{EF}$ values suggest that ambient air quality of urban regions of Khuzestan is still far from the standards for good quality and low pollution. The performed linear regression of AQI with PMs $\left(\mathrm{PM}_{2.5}\right.$ and $\left.\mathrm{PM}_{10}\right)$ and air quality assessment based on EF demonstrates that PMs pollutants are responsible for high or critical pollution, which significantly deteriorate air quality in all studied regions. The obtained results also revealed that inconsis- tent pollution levels in different cities (i.e., Ahwaz and Abadan were the most polluted) could be due to varying levels of human activities, which makes it necessary to monitor and control these cities even more.

Finally, based on the assessment of spatial and temporal changes of air contaminants, it is possible to manage the air pollution in the studied areas using a scientific basis since these areas need urgent action to control these pollutions. The current investigation provides a good insight for urban contamination control in Khuzestan Province and can act as a basis for further studies and a guide to enforce required regulations by relevant authorities. Based on the obtained results, a region-oriented emission management approach is required to support further air quality improvement in Khuzestan Province. It must be mentioned that the performed investigation has some limitations and shortcomings.

First, the level of atmosphere contamination in urban regions is shown according to the average point-monitored concentrations in the area, which may cause extrapolation errors. Second, air quality can be affected by different factors such as meteorological conditions (relative humidity, temperature, and wind speed), the topographic status of the area (such as elevation and vegetation coverage), human activities, socioeconomic factors, and even health challenges (e.g., COVID-19 pandemic). These factors affect the quantitative analysis of air quality in the present research. In other words, any efficient contamination management requires evaluating 
spatiotemporal changes of PMs and determining their relationship with these parameters. In addition, there is a necessity for future studies to combine remote-sensed and ground-monitored data to manage extrapolation errors and investigate associations between air contaminants and other factors for more urban regions.

\section{Ethical Considerations}

\section{Compliance with ethical guidelines}

All ethical principles such as the informed consent of the participants, the confidentiality of information, the permission of the participants to cancel their participation in the research are considered in this article.

\section{Funding}

This study was extracted from a $\mathrm{PhD}$. dissertation of the second author at the Department of Environment Sciences, Faculty of Natural Resources and Environment, Malayer University, Malayer.

\section{Authors' contributions}

Conceptualization and supervision: Nasrin Hassanzadeh; Writing - original draft: Fariba Hedayatzadeh; Writing - review \& editing: Nasrin Hassanzadeh; Data collection, data curation, and data analysis: Fariba Hedayatzade; Validation: Nasrin Hassanzadeh; Methodology and funding acquisition and resources: All authors.

\section{Conflict of interest}

The authors declared no conflict of interest.

\section{Acknowledgments}

The authors would like to thank the manager of the Air Quality Monitoring Center of Khuzestan Province for his cooperation.

\section{References}

[1] Chen L, Shi M, Gao S, Li S, Mao J, Zhang H, et al. Assessment of population exposure to $\mathrm{PM}_{25}$ for mortality in China and its public health benefit based on BenMAP. Environ Pollut. 2017; 221:311-7. [DOI:10.1016/j.envpol.2016.11.080] [PMID]

[2] Nducol N, Tchuente Siaka YF, Younui Yakum-Ntaw S, Saidou, Dika Manga J, Vardamides JC, et al. Ambient air particle mass concentrations in the urban area of the capital city of Yaoundé (Cameroon, Central Africa): Monthly and seasonal behavior. Int J Environ Anal Chem. 2020:1-17. [DOI:10.1080/ 03067319.2020.1715378]

[3] Nowak DJ, Hirabayashi S, Bodine A, Greenfield E. Tree and forest effects on air quality and human health in the United States. Environ Pollut. 2014; 193:119-29. [DOI:10.1016/j.envpol.2014.05.028] [PMID]

[4] Dadhich AP, Goyal R, Dadhich PN. Assessment of spatiotemporal variations in the air quality of Jaipur city, Rajasthan, India. Egypt J Remote Sens. 2018; 21(2):173-81. [DOI:10.1016/j.ejrs.2017.04.002]

[5] Momtazan M, Geravandi S, Rastegarimehr B, Valipour A, Ranjbarzadeh A, Yari AR, et al. An investigation of particulate matter and relevant cardiovascular risks in Abadan and Khorramshahr in 2014-2016. Toxin Rev. 2018:290-7. [DOI:10.1 080/15569543.2018.1463266]

[6] Ma Z, Hu X, Sayer AM, Levy R, Zhang Q, Xue Y, et al. Satellite-based spatiotemporal trends in $\mathrm{PM}_{25}$ concentrations: China, 2004-2013. Environ Health Perspect. 2016; 124(2):184-92. [DOI:10.1289/ehp.1409481] [PMID] [PMCID]

[7] Brauer M, Freedman G, Frostad J, Van Donkelaar A, Martin RV, Dentener F, et al. Ambient air pollution exposure estimation for the global burden of disease 2013. Environ Sci Technol. 2016; 50(1):79-88. [DOI:10.1021/acs.est.5b03709] [PMID]

[8] Karagulian F, Belis CA, Dora CFC, Prüss-Ustün AM, Bonjour S, Adair-Rohani $\mathrm{H}$, et al. Contributions to cities' ambient Particulate Matter (PM): A systematic review of local source contributions at global level. Atmos Environ. 2015; 120:475-83. [DOI:10.1016/j.atmosenv.2015.08.087]

[9] Clements N, Hannigan MP, Miller SL, Peel JL, Milford JB. Comparisons of urban and rural $\mathrm{PM}_{10-25}$ and $\mathrm{PM}_{25}$ mass concentrations and semi-volatile fractions in northeastern Colorado. Atmos Chem Phys. 2016; 16(11):7469-84. [DOI:10.5194/ acp-16-7469-2016]

[10] Tiwari S, Bisht D, Srivastava A, Pipal A, Taneja A, Srivastava $\mathrm{M}$, et al. Variability in atmospheric particulates and meteorological effects on their mass concentrations over Delhi, India. Atmos Res 2014; 145:45-56. [DOI:10.1016/j.atmosres.2014.03.027]

[11] Lu F, Xu D, Cheng Y, Dong S, Guo C, Jiang X, et al. Systematic review and meta-analysis of the adverse health effects of ambient $\mathrm{PM}_{2.5}$ and $\mathrm{PM}_{10}$ pollution in the Chinese population. Environ Res. 2015; 136:196-204. [DOI:10.1016/j. envres.2014.06.029] [PMID]

[12] Anderson JO, Thundiyil JG, Stolbach A. Clearing the air: A review of the effects of particulate matter air pollution on human health. J Med Toxicol. 2012; 8(2):166-75. [DOI:10.1007/ s13181-011-0203-1] [PMID] [PMCID]

[13] Li C, Dai Z, Yang L, Ma Z. Spatiotemporal characteristics of air quality across Weifang from 2014-2018. Int J Environ Res Public Health 2019; 16(17):3122. [DOI:10.3390/ijerph16173122] [PMID] [PMCID]

[14] Kala J, Sharma G, Kumar S, Pipralia S. Study of ambient air quality status on urban roads using air quality index-a case of Jaipur City (Rajasthan, India). IJTAS. 2014; 6(1):138. http:// citeseerx.ist.psu.edu/viewdoc/download?doi=10.1.1.689.145 $9 \&$ rep=rep $1 \&$ type $=$ pdf

[15] Jaafari J, Naddafi K, Yunesian M, Nabizadeh R, Hassanvand MS, Ghozikali MG, et al. Study of $\mathrm{PM}_{10^{\prime}} \mathrm{PM}_{2.5^{\prime}}$ and PM1 levels in during dust storms and local air pollution events in 
urban and rural sites in Tehran. Hum Ecol Risk Assess. 2018; 24(2):482-93. [DOI:10.1080/10807039.2017.1389608]

[16] Querol X, Tobías A, Pérez N, Karanasiou A, Amato F, Stafoggia $\mathrm{M}$, et al. Monitoring the impact of desert dust outbreaks for air quality for health studies. Environ Int. 2019; 130 104867. [DOI:10.1016/j.envint.2019.05.061] [PMID] [PMCID]

[17] Goudarzi G, Idani E, Alavi N, Salmanzadeh S, Babaei AA, Geravandi S, et al. Association of polycyclic aromatic hydrocarbons of the outdoor air in Ahvaz, southwest Iran during warm-cold season. Toxin Rev. 2017; 36(4):282-9. [DOI:10.1080 /15569543.2017.1304422]

[18] Maleki H, Sorooshian A, Goudarzi G, Nikfal A, Baneshi MM. Temporal profile of $\mathrm{PM}_{10}$ and associated health effects in one of the most polluted cities of the world (Ahvaz, Iran) between 2009 and 2014. Aeolian Res. 2016; 22:135-40. [DOI:10.1016/j.aeolia.2016.08.006] [PMID] [PMCID]

[19] Goudarzi G, Geravandi S, Foruozandeh H, Babaei AA, Alavi N, Niri MV, et al. Cardiovascular and respiratory mortality attributed to ground-level ozone in Ahvaz, Iran. Environ Monit Assess. 2015; 187(8):1-9. [DOI:10.1007/s10661-0154674-4] [PMID]

[20] Khaefi M, Goudarzi G, Yari AR, Geravandi S, Dobaradaran S, Idani E, et al. An association between ambient pollutants and hospital admitted respiratory cases in Ahvaz, Iran. Fresenius Environ Bull. 2016; 25(10):3955-3961. https:// www.researchgate.net/ profile/Buelent-Verep/publication/309281580

[21] Yari AR, Goudarzi G, Geravandi S, Dobaradaran S, Yousefi F, Idani E, et al. Study of ground-level ozone and its health risk assessment in residents in Ahvaz City, Iran during 2013 Toxin Rev. 2016; 35(3-4):201-6. [DOI:10.1080/15569543.2016.1 225769]

[22] Goudarzi G, Alavi N, Geravandi S, Idani E, Behrooz HRA, Babaei AA, et al. Health risk assessment on human exposed to heavy metals in the ambient air PM 10 in Ahvaz, southwest Iran. Int J Biometeorol 2018; 62(6):1075-83. [DOI:10.1007/ s00484-018-1510-x] [PMID]

[23] Taghavi F, Owlad E, Ackerman S. Enhancement and identification of dust events in the southwest region of Iran using satellite observations. J Earth Syst Sci. 2017; 126(2):28. [DOI:10.1007/s12040-017-0808-0]

[24] Pandey P, Patel D, Khan A, Barman S, Murthy R, Kisku G. Temporal distribution of fine particulates $\left(\mathrm{PM}_{25^{\prime}} \mathrm{PM}_{10}\right)$, potentially toxic metals, PAHs and Metal-bound carcinogenic risk in the population of Lucknow City, India. J Environ Sci Health A. 2013; 48(7):730-45. [DOI:10.1080/10934529.2013.74 4613] [PMID]

[25] Ebenstein A, Fan M, Greenstone M, He G, Zhou M. New evidence on the impact of sustained exposure to air pollution on life expectancy from China's Huai River Policy. PNAS. 2017; 114(39):10384-9. [DOI:10.1073/pnas.1616784114] [PMID] [PMCID]

[26] Zhang X, Zhang X, Chen X. Happiness in the air: How does a dirty sky affect mental health and subjective well-being? J Environ Econ Manage. 2017; 85:81-94. [DOI:10.1016/j. jeem.2017.04.001] [PMID] [PMCID]

[27] Dèdelè A, Miškinytè A. Seasonal and site-specific variation in particulate matter pollution in Lithuania. Atmos Pollut Res. 2019; 10(3):768-75. [DOI:10.1016/j.apr.2018.12.004]
[28] Gautam S, Brema J. Spatio-temporal variation in the concentration of atmospheric particulate matter: A study in fourth largest urban agglomeration in India. Environ Technol Innov. 2020; 17:100546. [DOI:10.1016/j.eti.2019.100546]

[29] Kuerban M, Waili Y, Fan F, Liu Y, Qin W, Dore AJ, et al. Spatio-temporal patterns of air pollution in China from 2015 to 2018 and implications for health risks. Environ Pollut. 2020; 258:113659. [DOI:10.1016/j.envpol.2019.113659] [PMID]

[30] Sun X, Luo XS, Xu J, Zhao Z, Chen Y, Wu L, et al. Spatiotemporal variations and factors of a provincial $\mathrm{PM}_{25}$ pollution in eastern China during 2013-2017 by geostatistics. Sci Rep. 2019; 9(1):1-10. [DOI:10.1038/s41598-019-40426-8] [PMID] [PMCID]

[31] Alizadeh-Choobari O, Bidokhti A, Ghafarian P, Najafi M. Temporal and spatial variations of particulate matter and gaseous pollutants in the urban area of Tehran. Atmos Environ. 2016; 141:443-53. [DOI:10.1016/j.atmosenv.2016.07.003]

[32] Barzeghar V, Sarbakhsh P, Hassanvand MS, Faridi S, Gholampour A. Long-term trend of ambient air $\mathrm{PM}_{10^{\prime}} \mathrm{PM}_{25^{\prime}}$ and $\mathrm{O}_{3}$ and their health effects in Tabriz City, Iran, during 2006-2017. Sustain Cities Soc. 2020; 54:101988. [DOI:10.1016/j. scs.2019.101988]

[33] Goudarzi G, Shirmardi M, Khodarahmi F, Hashemi-Shahraki A, Alavi N, Ankali KA, et al. Particulate matter and bacteria characteristics of the Middle East Dust (MED) storms over Ahvaz, Iran. Aerobiologia. 2014; 30(4):345-56. [DOI:10.1007/ s10453-014-9333-7]

[34] Kianisadr M, Ghaderpoori M, Jafari A, Karami M. Zoning of air quality index $\left(\mathrm{PM}_{10}\right.$ and $\left.\mathrm{PM}_{25}\right)$ by Arc-GIS for Khorramabad city, Iran. Data Brief. 2018:1131-41. [DOI:10.1016/j. dib.2018.05.063] [PMID] [PMCID]

[35] Yousefi S, Shahsavani A, Hadei M. Applying EPA's instruction to calculate Air Quality Index (AQI) in Tehran. J Health Pollut. 2019; 4(2):816. [DOI:10.18502/japh.v4i2.1232]

[36] Mariselvam A, Kumar M, Dharmaraj C, Maharaj E, Dhasarathan N, Sivanesan S. Assessment of air quality index of urban area and epidemiological investigations in Chennai. J Environ Biol. 2019; 40(4):790-5. [DOI:10.22438/jeb/40/4(SI)/JEB_21]

[37] Jumaah HJ, Ameen MH, Kalantar B, Rizeei HM, Jumaah SJ. Air quality index prediction using IDW geostatistical technique and OLS-based GIS technique in Kuala Lumpur, Malaysia. Geomatics Nat Hazards Risk. 2019; 10(1):2185-99. [DO I:10.1080/19475705.2019.1683084]

[38] Haque M, Singh R. Air pollution and human health in Kolkata, India: A case study. Climate. 2017; 5(4):77. [DOI:10.3390/ cli5040077]

[39] Shukla U, Manjunath N. Studies on air quality status at selected pockets of Indian Capital Delhi. Int Res J Eng Technol. 2018; 5(8):416-20. https://d1wqtxts1xzle7.cloudfront. net/57385197/IRJET-V5I873.pdf?

[40] Nihalani S, Kadam S, editors. Ambient air quality assessment for Vadodara City using AQI and exceedence factor. ICACM. 2019 [Published Online]. [DOI:10.2139/ssrn.3464926]

[41] Masoudi M, Elhaeesahar M. Trend assessment of climate changes in Khuzestan Province, Iran. Natural Environment Change. 2016; 2(2):143-52. https://jnec.ut.ac.ir/article_60997_6 6bcfb995da2a7c9f5032d7cdae2d6d5.pdf 
[42] Khavarian-Garmsir AR, Pourahmad A, Hataminejad H, Farhoudi R. A comparative assessment of economic and physical inequality between shrinking and growing cities: A case study of Khuzestan province, Iran Int J Urban Sci. 2018; 22(1):104-22. [DOI:10.1080/12265934.2017.1358653]

[43] Banerjee T, Srivastava RK. Assessment of the ambient air quality at the Integrated Industrial Estate-Pantnagar through the Air Quality Index (AQI) and Exceedence Factor (EF). AsiaPac J Chem Eng. 2011; 6(1):64-70. [DOI:10.1002/apj.450]

[44] Rao M, Rao H. Air pollution (pp. 268-271). New Delhi: Tata McGraw Hill Publishing Company Limited; 2001. https:// books.google.com/books?id=

[45] Shooter D, Brimblecombe P. Air quality indexing.Int J Environ Pollut. 2009; 36(1-3):305-23. [DOI:10.1504/IJEP.2009.021834]

[46] Sarasamma JD, Narayanan BK. Air quality assessment in the surroundings of KMML industrial area, Chavara in Kerala, South India. Aerosol Air Qual Res. 2014; 14(6):1769-78. [DOI:10.4209/aaqr.2013.10.0327]

[47] Kundu Chowdhury A, Debsarkar A, Chakrabarty S. Assessment of seasonal variations of average traffic pollution levels in curbside open-air microenvironments in Kolkata, India. Health Scope. 2016; 5(2):e33081. [DOI:10.17795/jhealthscope-33081]

[48] Kumar S, Srinivas N, Sunil K. Monitoring and assessment of air quality with reference to dust particles $\left(\mathrm{PM}_{10}\right.$ and $\mathrm{PM}_{2}$ ${ }_{5}$ ) in urban environment. Int J Res Eng Tech. 2014; 3:2321-7308. [DOI:10.15623/ijret.2014.0328009]

[49] Daniali M, Karimi N. Spatiotemporal analysis of dust patterns over Mesopotamia and their impact on Khuzestan province, Iran. Nat Hazards. 2019; 97(1):259-81. [DOI:10.1007/ s11069-019-03641-0]

[50] Masoudi M, Asadifard E, Rastegar M. Status of $\mathrm{PM}_{10}$ as an air pollutant and its prediction using meteorological parameters in Ahvaz, Iran. Nat Resour Res. 2018; 6(2):163-74. https://iranjournals.nlai.ir/handle/123456789/333882

[51] Ahmadi M, Dadashirodbari A, Jafari M. [The effect of boundary layer height height on dust storm in southwest of iran (case study: february 21-24, 2016) (Persian)]. Nat Hazards (Dordr) Nat Hazards. 2019; 8(19):151-74. https://jneh.usb.ac.ir/article_ 3878_4ca7ec9104e8be4587dd707e34e17a97.pdf?lang=en

[52] Shahsavani A, Naddafi K, Haghighifard NJ, Mesdaghinia A, Yunesian M, Nabizadeh R, et al. The evaluation of $\mathrm{PM}_{10}$ $\mathrm{PM}_{25^{\prime}}$ and PM1 concentrations during the Middle Eastern Dust (MED) events in Ahvaz, Iran, from April through September 2010. J Arid Environ. 2012; 77:72-83. [DOI:10.1016/j. jaridenv.2011.09.007]

[53] Daryanoosh M, Goudarzi G, Rashidi R, Keishams F, Hopke PK, Mohammadi MJ, et al. Risk of morbidity attributed to ambient PM10 in the western cities of Iran. Toxin Rev. 2018; 37(4):313-8. [DOI:10.1080/15569543.2017.1370602]

[54] Mehrabi S, Soltani S, Jafari R. Analyzing the relationship between dust storm occurrence and climatic parameters. J Agric Sci Technol. 2015; 19(71):69-81. [DOI:10.18869/acadpub.jstnar.19.71.69]

[55] Jahanbakhsh S, Zeinali B, Asghari S. [Analysis and clustering of dust storm frequency in Iran by Fuzzy Clustering (FCM). J Urban Ecol Res. 2014; 5(10):85-98. http://grup. journals.pnu.ac.ir/article_1662_89a37bf872836e8de5fd5812 9f325815.pdf?lang=en
[56] Khodarahmi F, Soleimani Z, Yousefzadeh S, Alavi N, Babaei AA, Mohammadi MJ, et al. Levels of $\mathrm{PM}_{10}, \mathrm{PM}_{25}$ and PM1 and impacts of meteorological factors on particle matter concentrations in dust events and non dusty days. Int J Health Sci. 2016; 1(3):7-12. [DOI:10.22100/ijhs.v1i3.63]

[57] Zhao D, Chen H, Yu E, Luo T. $\mathrm{PM}_{2.5} / \mathrm{PM}_{10}$ ratios in eight economic regions and their relationship with meteorology in China. Adv Meteorol. 2019; 2019. [DOI:10.1155/2019/5295726]

[58] Zakey AS, Abdel-Wahab MM, Pettersson JC, Gatari MJ, Hallquist M. Seasonal and spatial variation of atmospheric particulate matter in a developing megacity, the Greater Cairo, Egypt. Atmosfera. 2008; 21(2):171-89. http://www.scielo. org.mx/scielo.php?pid=S0187-62362008000200004

[59] Xu G, Jiao L, Zhang B, Zhao S, Yuan M, Gu Y, et al. Spatial and temporal variability of the $\mathrm{PM}_{25} / \mathrm{PM}_{10}$ ratio in $\mathrm{Wu}$ han, Central China. Aerosol Air Qual Res. 2017; 17(3):741-51. [DOI:10.4209/aaqr.2016.09.0406]

[60] Eslami A, Atafar Z, Pirsaheb M, Asadi F. [Trends of particulate matter $\left(\mathrm{PM}_{10}\right)$ concentration and related Air Quality Index (AQI) during 2005-2012 in Kermanshah, Iran (Persian)] 2014; 2(1):3-28. https://journals.sbmu.ac.ir/en-jhf/article/ view/15948

[61] Amarloei A, Fazlzadeh M, Jafari AJ, Zarei A, Mazloomi S. Particulate matters and bioaerosols during Middle East dust storms events in Ilam, Iran. Microchem J. 2020; 152:104280. [DOI:10.1016/j.microc.2019.104280]

[62] Kamarehie B, Ghaderpoori M, Jafari A, Karami M, Mohammadi A, Azarshab K, et al. Estimation of health effects (morbidity and mortality) attributed to $\mathrm{PM}_{10}$ and $\mathrm{PM}_{2.5}$ exposure using an Air Quality model in Bukan city, from 20152016 exposure using air quality model. Environ Eng Manag J. 2017; 4(3):137-42. [DOI:10.15171/EHEM.2017.19]

[63] Trivedi DK, Ali K, Beig G. Impact of meteorological parameters on the development of fine and coarse particles over Delhi. Sci Total Environ. 2014; 478:175-83. [DOI:10.1016/j.scitotenv.2014.01.101] [PMID]

[64] Xu Y, Liu H. Spatial ensemble prediction of hourly $\mathrm{PM}_{2.5}$ concentrations around Beijing railway station in China. Air Qual Atmos Health . 2020; 13(5):563-73. [DOI:10.1007/s11869020-00817-7]

[65] Xu L, Batterman S, Chen F, Li J, Zhong X, Feng Y, et al. Spatiotemporal characteristics of $\mathrm{PM}_{2.5}$ and $\mathrm{PM}_{10}$ at urban and corresponding background sites in 23 cities in China. Sci Total Environ. 2017; 599: 2074-84. [DOI:10.1016/j.scitotenv.2017.05.048] [PMID] [PMCID]

[66] Liu J, Mauzerall DL, Chen Q, Zhang Q, Song Y, Peng W, et al. Air pollutant emissions from Chinese households: A major and underappreciated ambient pollution source. PNAS. 2016; 113(28):7756-61. [DOI:10.1073/pnas.1604537113] [PMID] [PMCID]

[67] Shen GF, Yuan SY, Xie YN, Xia SJ, Li L, Yao YK, et al. Ambient levels and temporal variations of $\mathrm{PM}_{2.5}$ and $\mathrm{PM}_{10}$ at a residential site in the mega-city, Nanjing, in the western Yangtze River Delta, China. J Environ Sci Health A. 2014; 49(2):171-8. [DOI:10.1080/10934529.2013.838851] [PMID]

[68] Bisht D, Srivastava A, Pipal A, Srivastava M, Pandey A, Tiwari S, et al. Aerosol characteristics at a rural station in southern peninsular India during CAIPEEX-IGOC: physical and chemi- 
cal properties. Environ Sci Pollut Res. 2015; 22(7):5293-304. [DOI:10.1007/s11356-014-3836-1] [PMID]

[69] Zhang F, Liu X, Zhou L, Yu Y, Wang L, Lu J, et al. Spatiotemporal patterns of Particulate Matter (PM) and associations between PM and mortality in Shenzhen, China. BMC Public Health. 2016; 16(1):1-11. [DOI:10.1186/s12889-0162725-6] [PMID] [PMCID]

[70] Lin B, Zhu J. Changes in urban air quality during urbanization in China. J Clean Prod. 2018; 188: 312-21. [DOI:10.1016/j. jclepro.2018.03.293]

[71] Dai W, Yi L. Spatio-temporal differences and driving forces of air quality in Chinese cities. J Resour Ecol. 2016; 7(2):77-84. [DOI:10.5814/j.issn.1674-764x.2016.02.001]

[72] Dastoorpoor M, Idani E, Goudarzi G, Khanjani N. Acute effects of air pollution on spontaneous abortion, premature delivery, and stillbirth in Ahvaz, Iran: A time-series study. Environ Sci Pollut Res. 2018; 25(6):5447-58. [DOI:10.1007/ s11356-017-0692-9] [PMID]

[73] Wang A, Jing J, Luo F, Liang L. Analysis of aqi change characteristics and correlation with $\mathrm{PM}_{2.5}$ And $\mathrm{PM}_{10}$ in beijing-tianjin-hebei region. Int Arch Photogramm Remote Sens. 2020; 42:1041-8. [DOI:10.5194/isprs-archives-XLII3-W10-1041-2020]

[74] Robert D, Pirro I. A comparative study of ambient air quality status in major cities of Albania. Ann "VALAHIA" Uni Targoviste. 2014; 8. https://d1wqtxts1xzle7.cloudfront. net/42250768/pirro_icka_2014.pdf? 